\title{
Experimental assessment of the seismic behavior of unbraced steel storage pallet racks
}

\author{
Alper Kanyilmaz*, Carlo Andrea Castiglioni, Giovanni Brambilla, Gian Paolo Chiarelli \\ Department of Architecture, Built Environment and Construction Engineering, ABC, Politecnico di Milano, Italy
}

\begin{abstract}
Steel storage racks are typically made of thin-walled cold formed steel profiles, which prove to be the most versatile, economic and sustainable elements for industrial rack construction. Their lightweight structural systems are usually designed to resist heavy load units, reaching considerable heights. However, the global behavior of storage racks under seismic actions is much less predictable than the be-havior of steel buildings made of standard steel profiles and connections, mainly due to the perforations in their thin walled upright columns, and their semi-rigid beam-column and base plate joints. Full scale experimental investigations are greatly needed in order to understand and quantify the global perfor-mance of storage racks, and improve their design for seismic actions.

For the first time in Europe, thanks to the funding provided by Research Fund for Coal and Steel (RFCS), an extensive full-scale push-over testing program has been carried out on 8 fully-loaded pallet racking specimens ( 4 unbraced and 4 braced racks), provided by 4 different international rack producers.

This paper presents the experimental results of full scale push-over tests performed in the down-aisle (longitudinal) direction on fully-loaded unbraced specimens. In particular, experimental global capacity curves of the tested specimens are presented, discussing the key factors influencing the racks' response, as well as the failure mechanisms of the different rack typologies. Furthermore, the behavior factor (q) values of each specimen are derived from re-analysis of the test results. Vulnerability of unbraced racks to soft-storey mechanism is demonstrated, highlighting its causes. Design guidelines are provided in order to guarantee a globally homogenous ductility under seismic actions, along with the new safety requirements for the design of the floor connections of unbraced racks.
\end{abstract}

\section{Introduction}

Steel storage racks are commonly used to store goods in warehouses. Their structural components are often made of thin walled perforated profiles to ensure modularity, adaptability and versatility needed in storing goods. Due to the high competitiveness of the logistics industry, they are designed as lightweight as possible to save on steel material costs. Despite the lightness of their structural systems, storage racks carry very high unit loads (an average $8-10 \mathrm{kN}$ per pallet), by far higher than their selfweight, contrary to typical loading in usual civil engineering structures.

Structural system of racks (Fig. 1) [1] is mainly composed of uprights (vertical members) made of perforated thin walled elements, and pallet beams (horizontal members), made of built-up closed sections linking adjacent frames, lying in the horizontal

\footnotetext{
* Corresponding author.

E-mail address: alper.kanyilmaz@polimi.it (A. Kanyilmaz).
}

direction parallel to the operating aisle. Diagonal elements (bracings) connect the uprights to each other in the cross-aisle (transversal) direction to form the upright frames, whereas the connections between the uprights and the pallet beam (beam-tocolumn joints) in down-aisle (longitudinal) direction are usually made of proprietary hook-in connectors welded to the pallet beam ends, and engaged into perforated holes in the uprights. Uprights are connected to the industrial floor by $L$ shaped components that are connected on the upright base on one leg, and on the floor on the other.

Stability of upright frames in cross-aisle direction is always provided by diagonal elements. On the other hand, in the downaisle direction, rack designers usually prefer avoiding bracings to make the shelves accessible on both sides from two aisles, allowing an efficient loading and unloading of goods in service. Therefore in unbraced racks, stability to lateral loads in the longitudinal direction is provided by the semi-rigid beam-to-column joints and base plate connections. Bracings may also be used in the down-aisle direction if required, especially when high seismic 


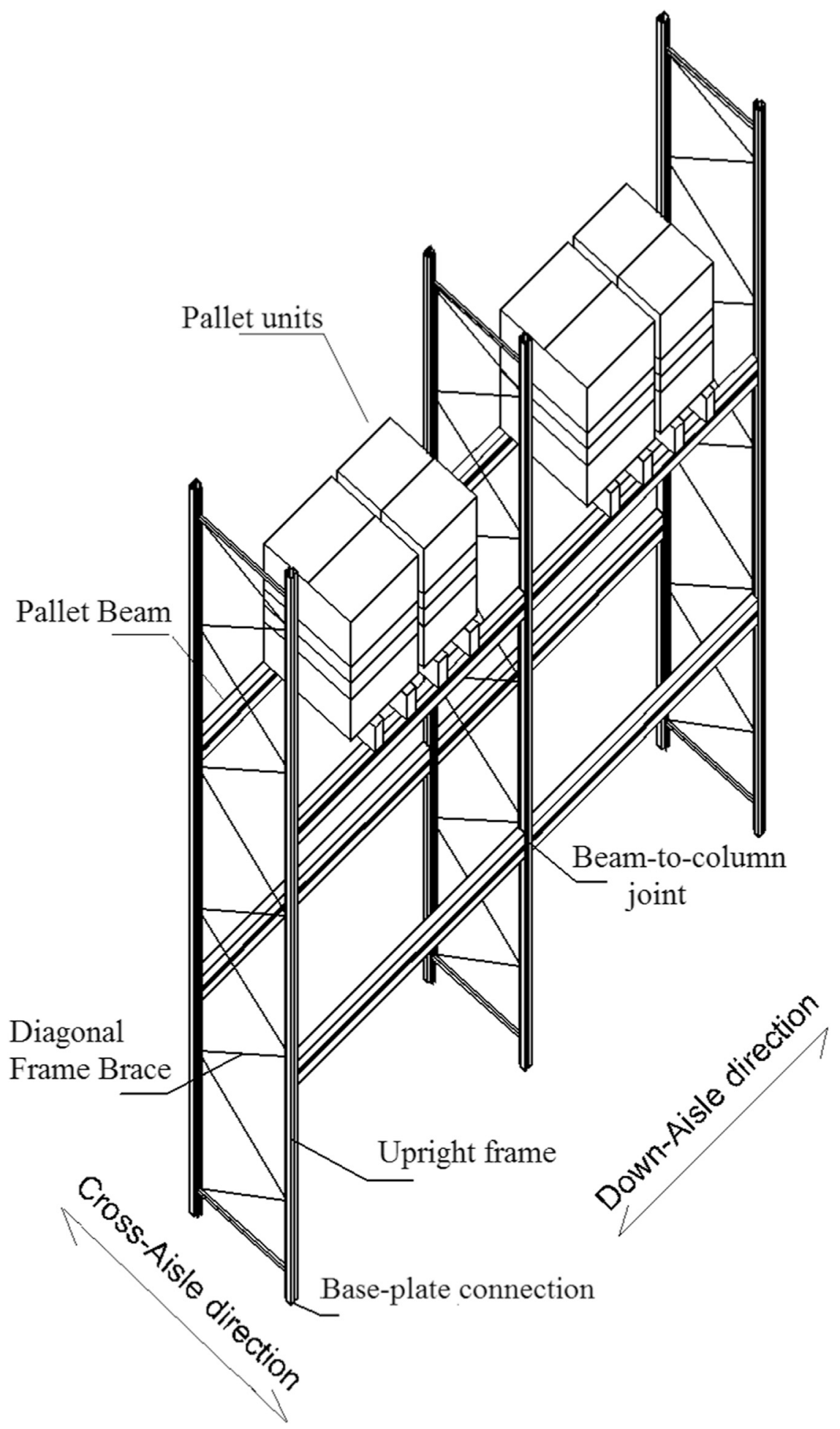

Fig. 1. Typical pallet rack configuration.

action is a concern. Different rack typologies are described by Pekoz et al. [2].

The design of storage racks is not a straight-forward task because of their peculiar structural forms, and difficulties predicting their structural behavior (both at global and local levels), which becomes even more complicated when storage racks are exposed to horizontal forces in seismic areas. Collapse of racks, during a seismic event, not only endangers the life of the employees and consumers (in case of "open to public" storage areas in shopping centers), but also results in a significant economic loss, much larger than the cost of the rack structure itself. Some examples observed after the recent Emilia-Romagna Earthquake (2012) are shown in Fig. 2 [3]. Picture a. shows the situation in a cheese factory where the racks were toppled down due to the absence of floor-connections. This was a very common type of collapse causing a significant economic loss in the area. In general, it is estimated that 633,700 wheels of Parmigiano Reggiano and Grana Padano cheese were damaged by falling off factory racks, with an 


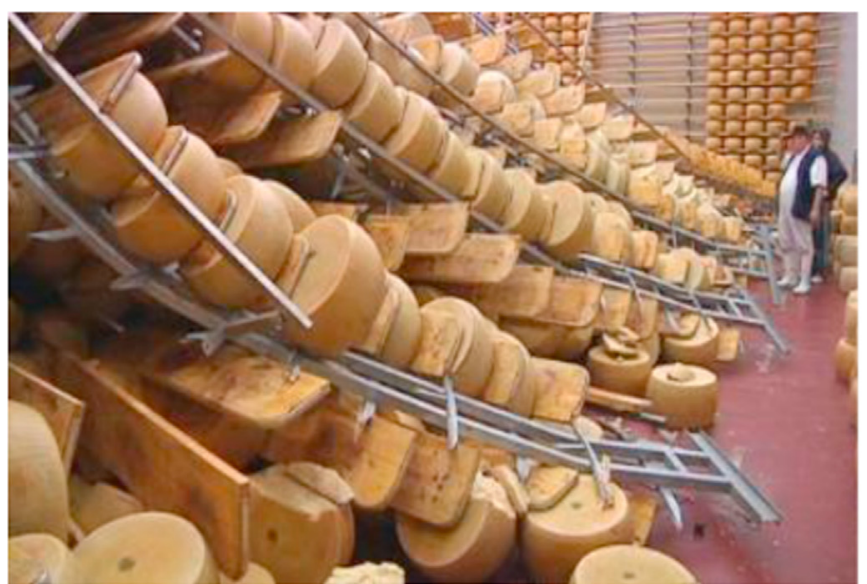

a

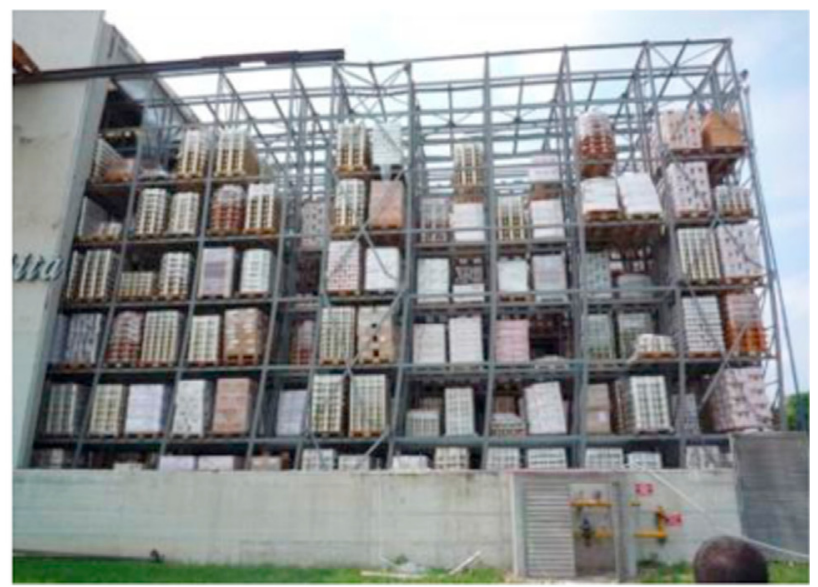

b

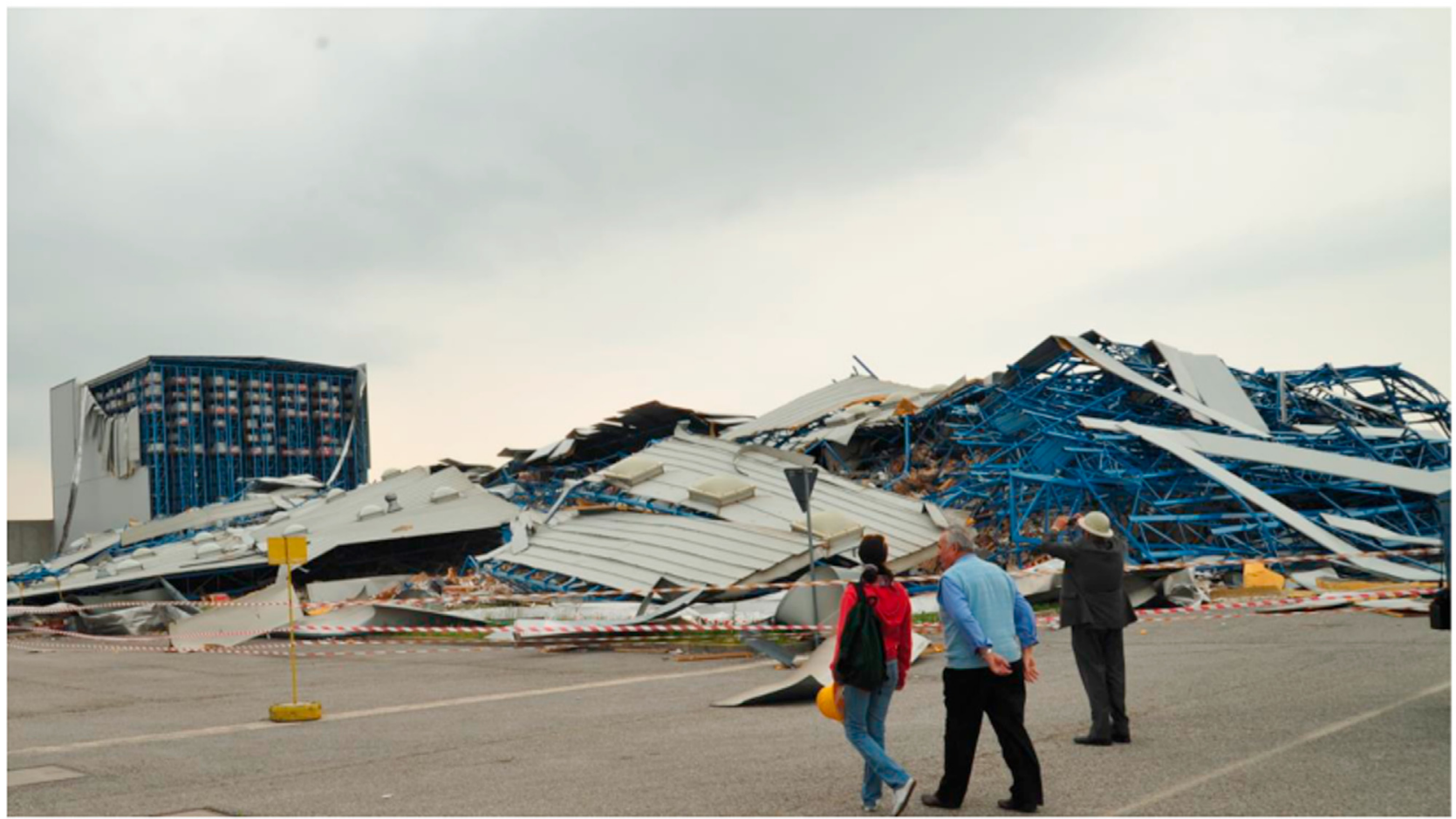

C

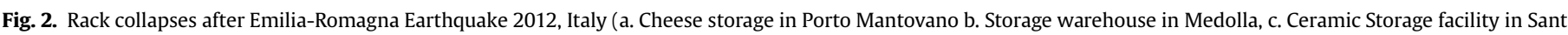
Agostino).

estimated cost of the damage about $€ 150$ million [4]. Picture b. presents a warehouse rack collapse where the rack system experienced permanent residual displacements over $1 \mathrm{~m}$ after the earthquake. In picture c., the collapse of the self-supporting ceramic storage warehouse in Sant'Agostino can be seen. To avoid these social and economic consequences, significant attention should be paid in the design and construction of storage racks located in seismic areas.

Seismic design of steel storage pallet racks is performed with an approach based upon the design philosophy of EN 1998-1 [5]. Seismic action is described by a design spectrum derived from the elastic spectrum by scaling it with the behavior factor q, which accounts for the ductility and damping of the racking structure. The reference values of behavior factor $\mathrm{q}$ for racks are given in accordance with their structural type, i.e. unbraced or braced racks. In unbraced racks (moment-resisting type), horizontal seismic forces are resisted by the flexural behavior of members and connections. Dissipative zones are mainly located in beam-toupright connections and in column bases, and the earthquake energy is dissipated by means of cyclic bending. The estimation of these parameters usually require experimental studies, even during the design phase.

Most of the experimental studies performed on the topic are mainly limited to experimental characterization of the cold formed rack components and joints at a local level (e.g beam-column and base plate connections, compression and tension tests on structural elements) [6-11]. Conclusions of these component-based studies indicate that the response of storage rack systems in their down-aisle direction are significantly influenced by the perforations in the upright profiles, and nonlinear rotational behavior of beam-to-upright and floor connections. However, the combinations of these various ductility resources have not been evaluated 
in full scale racks under horizontal loading. This paper provides a significant insight to this aspect, presenting the global behavior of real-scale storage racks under horizontal loading, and quantifying their global ductility capacities.

Full scale experiments performed previously only gave limited indications, for a limited number of rack configurations. The first available results of full scale testing, and analytical investigations on the seismic response of storage racks were published in the mid-1970s by John A. Blume and Associates [12]. Between 1979 and 1981, cantilever tests, portal tests, quasi-static tests of storage rack systems, dynamic tests (Krawinkler et al. [13]), shake-table tests, and merchandise tests (Chen et al. [14]) were performed.

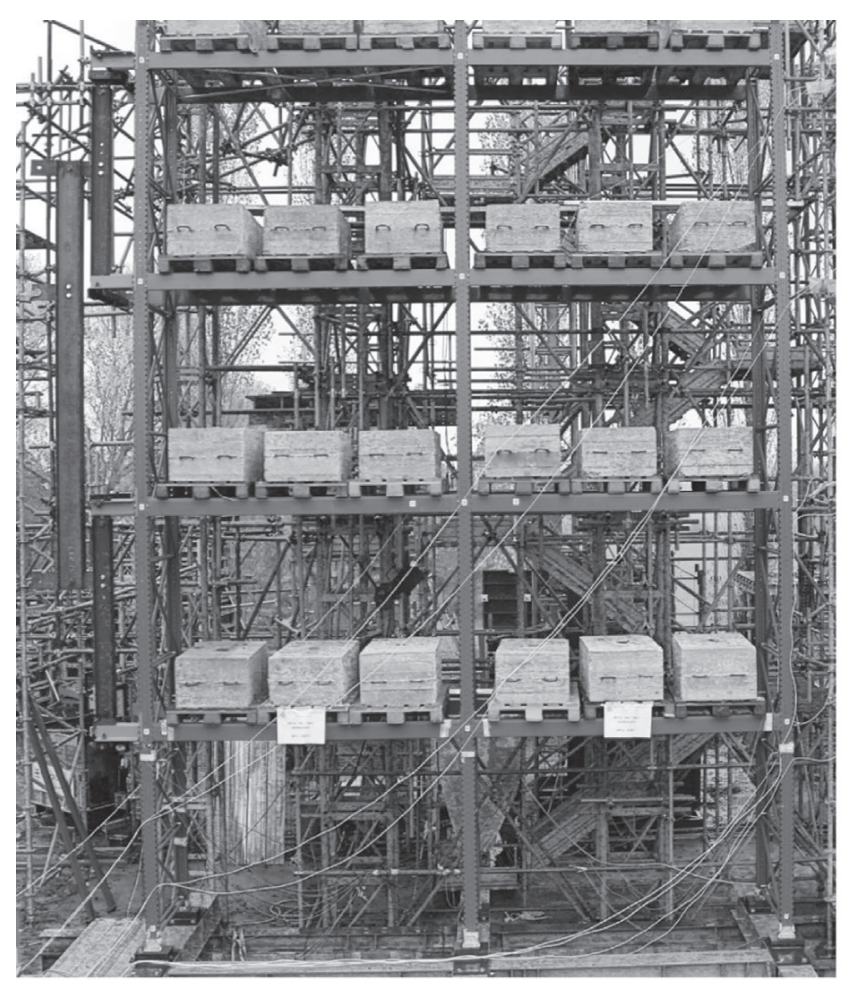

a. IPA1

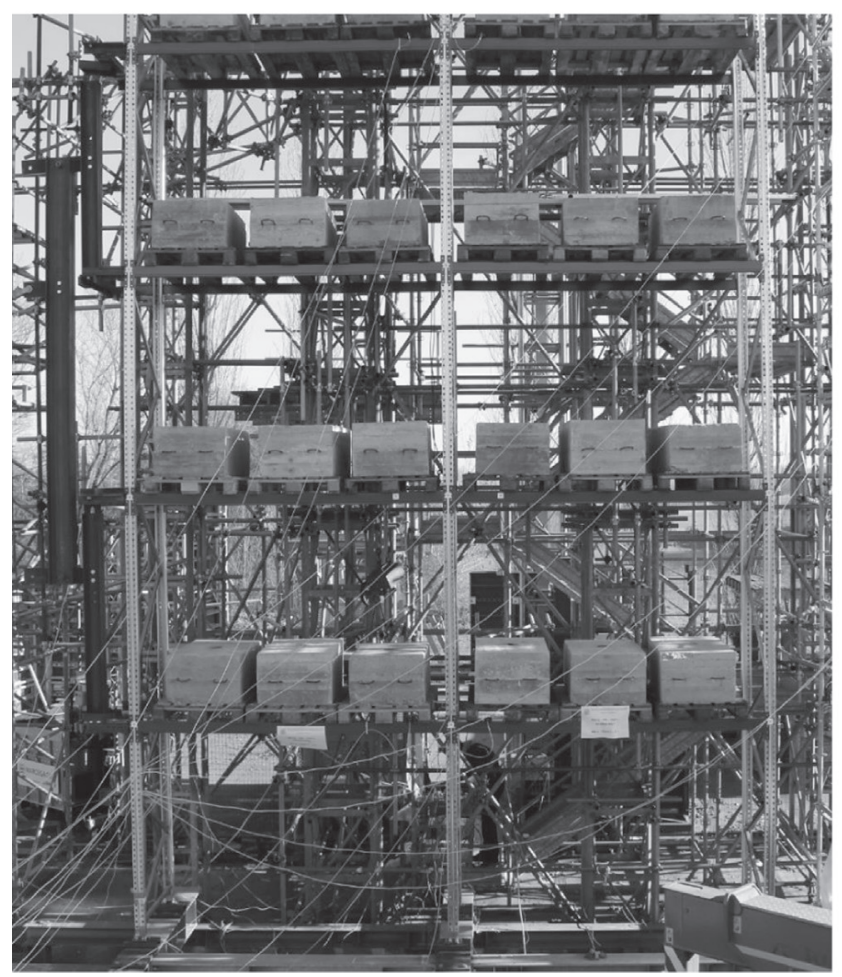

c. IPC1

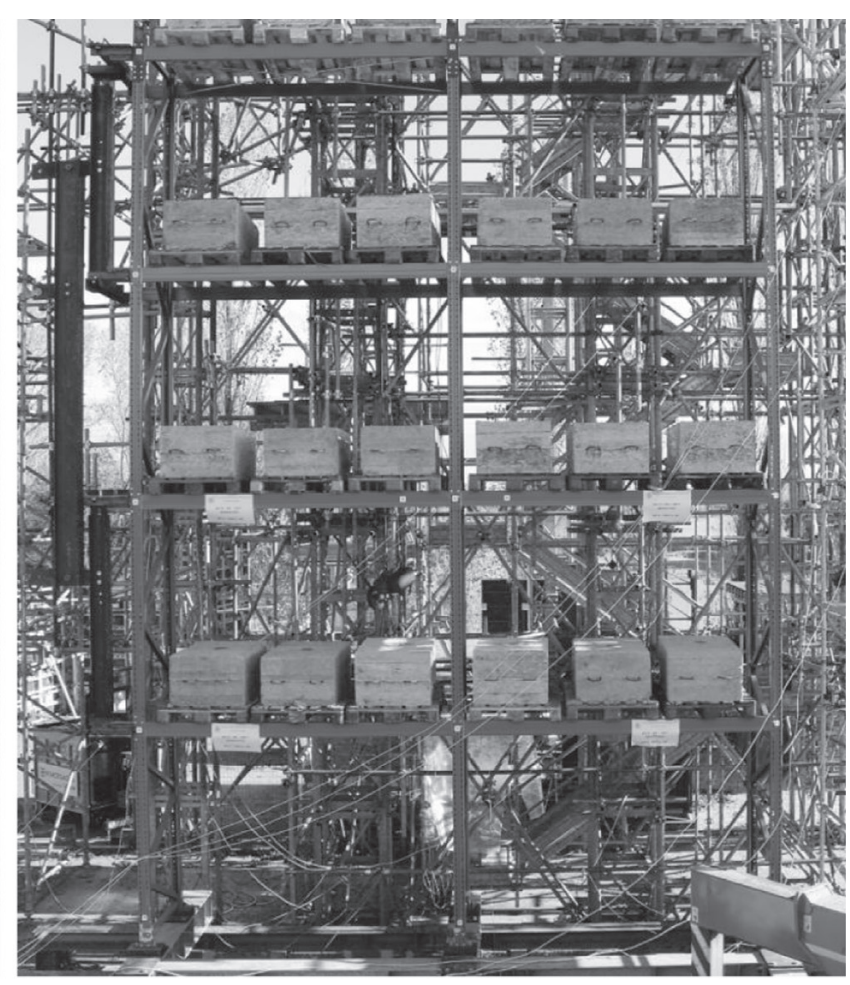

b. IPB1

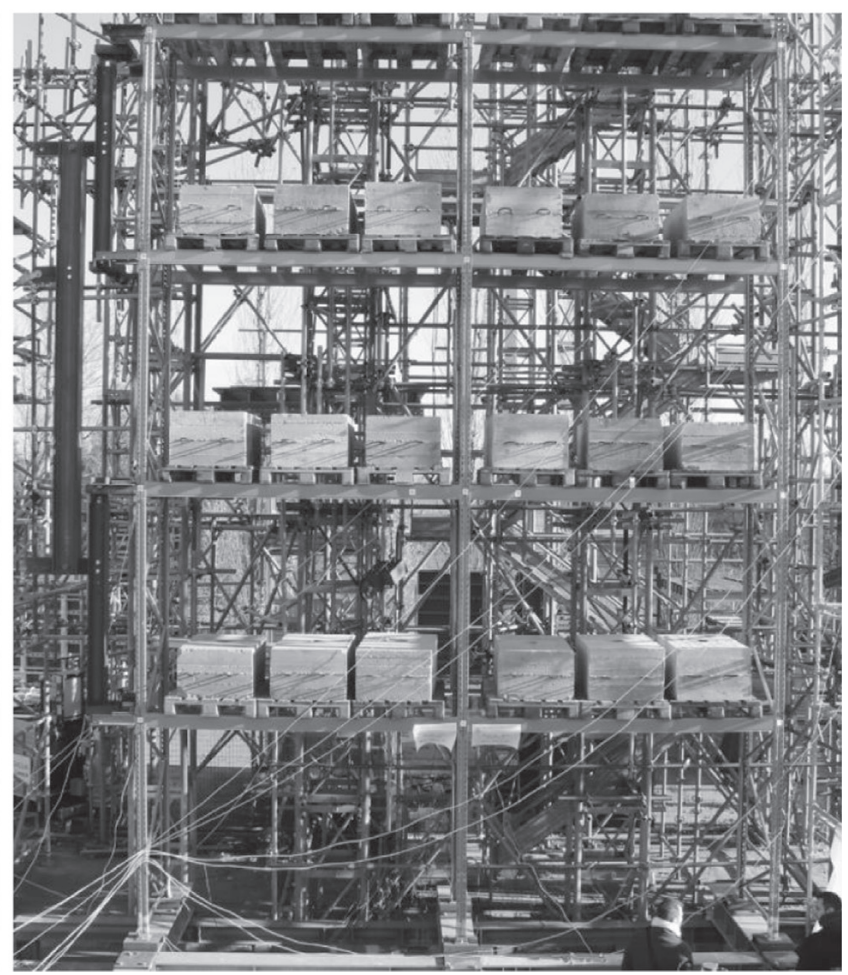

d. IPD1

Fig. 3. Pictures of test specimens. 
Filiatrault [15] tested five different back-to-back pallet racks loaded with real merchandise on a uniaxial shake-table under a single component, scaled at various amplitudes, under the ground motion recorded at Canoga Park during the 1994 Northridge earthquake. Three of the tests were performed in the cross-aisle direction, while the two other tests were performed in the down-aisle direction. The tests performed by Filiatrault et al. [16] on a shaketable indicated that the rotational stiffness of beam-to-up-right connections is the major factor influencing the down-aisle response of pallet racks under seismic actions. Gilbert et al. [17] performed full scale tests on a complete drive-in rack systems, in loaded and empty conditions. They presented the load transfer mechanism in the rack, and its relative stiffness under various horizontal loading conditions.

At European level, shake-table tests on four full-scale steel storage pallet racks loaded by concrete blocks mounted on pallets simulating merchandise have been performed within the ECsponsored ECOLEADER program [18], which highlighted the importance of the diagonal bracing configuration in both down-aisle and cross-aisle directions on the seismic response of steel storage

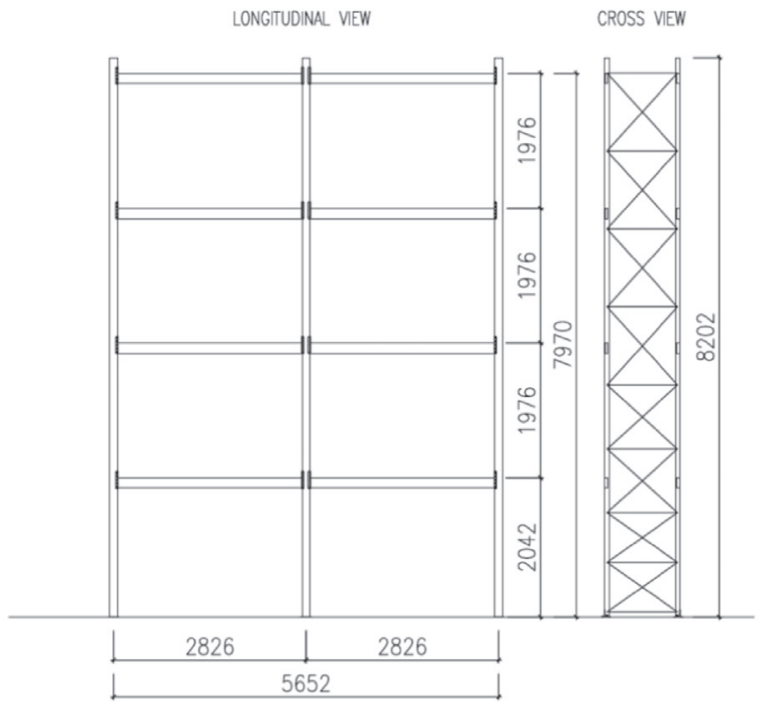

a. IPA1

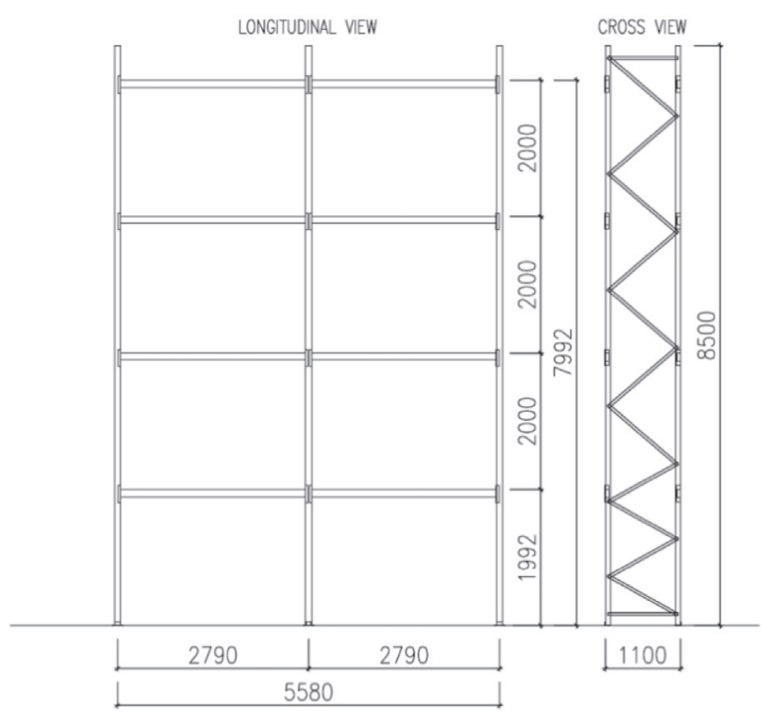

c. IPC1 pallet racks. SEISRACKS1 project [19-21] funded by the EU Research Fund for Coal and Steel mainly contributed to the definition of coefficients accounting for sliding and energy dissipation in the stored merchandizes, methods of analysis and ways to account for second order effects, and description of non-dissipative and dissipative design philosophy with associated values of behavior factors. Despite the satisfactory results achieved from a series of tests on the static and dynamic properties of steel storage racking systems, many questions remain open regarding ductility and energy dissipation capacity (and consequent q-factors) of several rack configurations widely adopted in practice.

In order to increase the knowledge on the global structural behavior and ductility of storage racks, a full scale testing program has been carried out within the research project "Seismic Behavior of Steel Storage Pallet Racking Systems" (SEISRACKS2) [22-29], thanks to financial support of EU Research Fund for Coal and Steel (RFCS). Tests have been performed on braced and unbraced pallet racks provided by different industrial partners of the project (Fig. 3).

This paper:

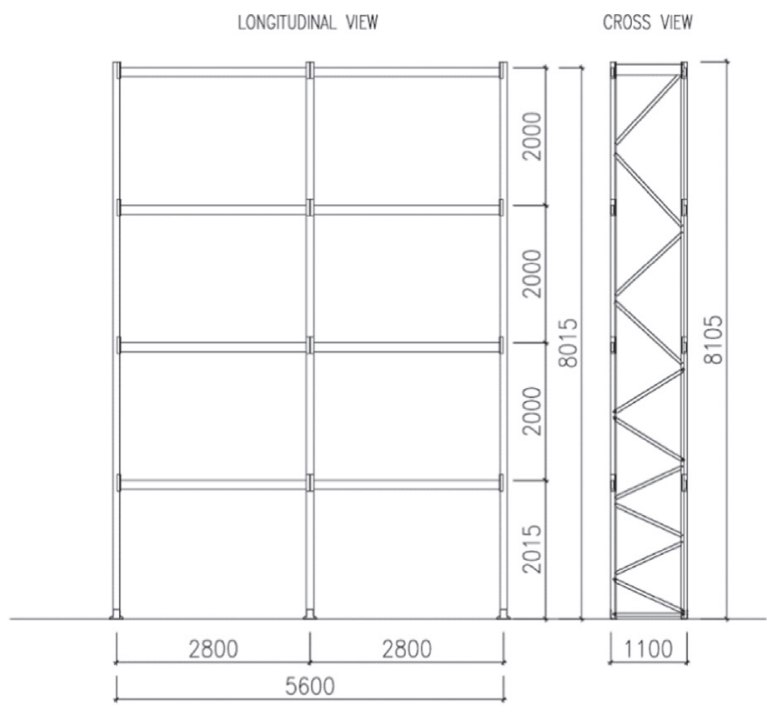

b. IPB1

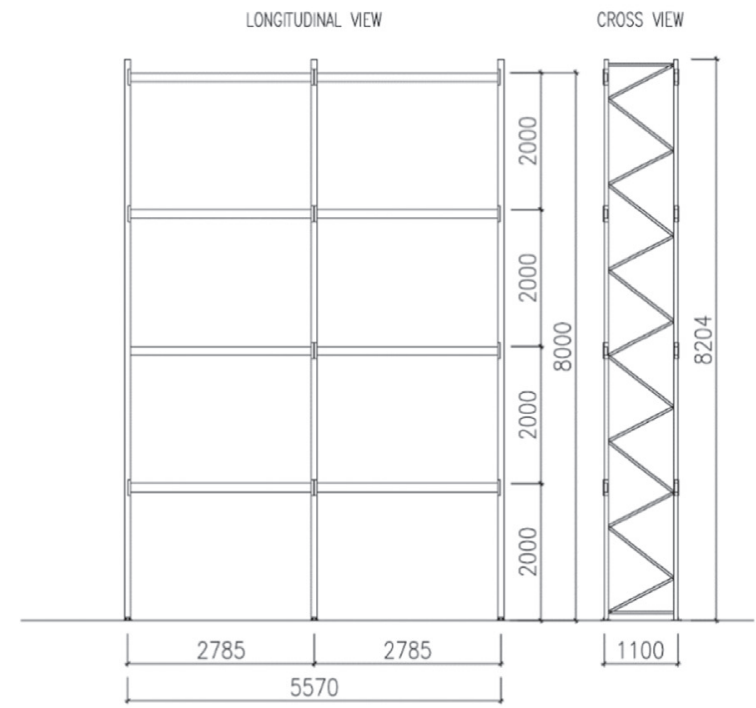

d. IPD1

Fig. 4. Geometry of test specimens. 


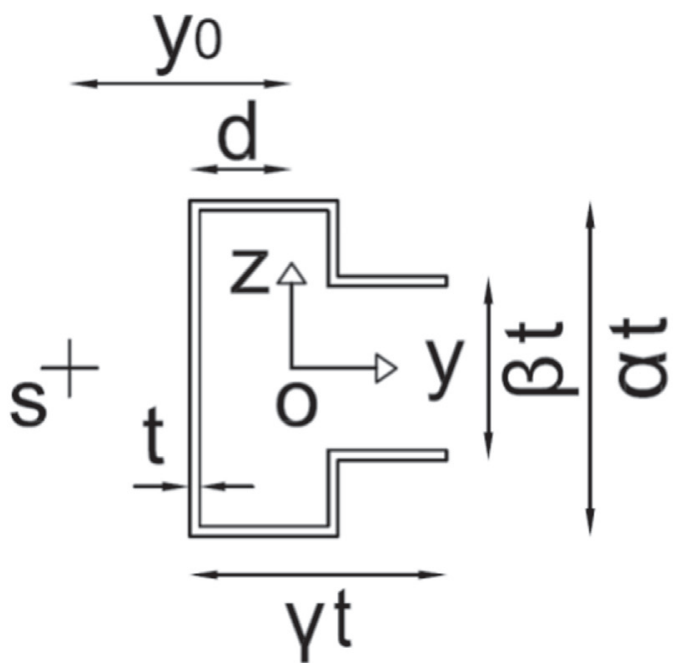

a. Upright cross-sections geometry

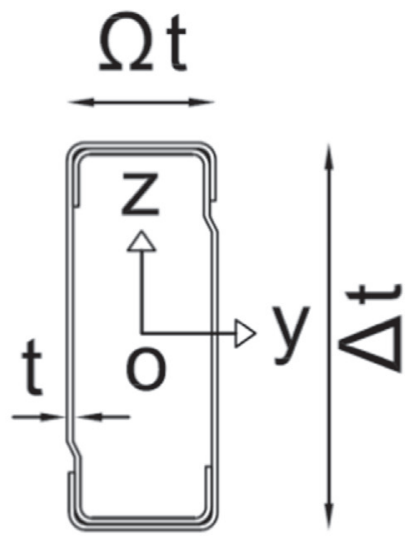

b. Pallet beam cross-section geometry

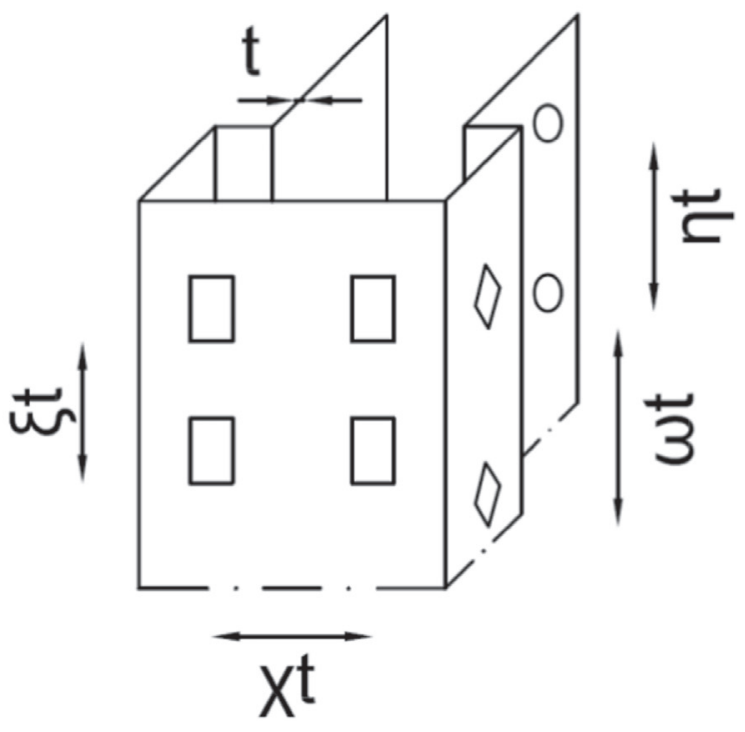

\section{c. Geometry of the holes of the upright cross-sections}

Fig. 5. Cross section and shape parameters of the rack specimens.

- presents the results of tests performed on unbraced rack specimens in terms of global capacity curves;

- discusses the key factors affecting the global horizontal response of unbraced racks;

- quantifies behavior factors (q) of the tested specimens, and compares them with design values;

- highlights the vulnerability of unbraced racks to soft storey mechanism

- provides design guidelines to avoid soft-storey mechanism;

- proposes safety requirements for the design of floor connections;

The first European Standard for the design of selective racking systems in seismic zones EN 16681 [30] developed by CEN TC344 introduced new safety requirements on floor connections based on the results of the present study.

\section{Experimental setup and test specimens}

To assess the global seismic response of unbraced racks in the down aisle direction, four full scale test specimens have been designed with different cold formed profiles, and identified as IPA1, IPB1, IPC1, and IPD1. The specimens are shown schematically in Fig. 4.

The cross section characteristics of the upright and beam profiles shown in Fig. 5, and their parameters are presented in Table 1 and Table 2, in terms of the steel grade, the ratio between the second moments of area $\left(\mathrm{I}_{\mathrm{y}} / \mathrm{I}_{\mathrm{z}}\right)$, the section moduli $\left(\mathrm{W}_{\mathrm{y}} / \mathrm{W}_{\mathrm{z}}\right)$ and radii of gyration $\left(\rho_{y} / \rho_{z}\right)$. In case of upright section, the ratio between effective and gross area $\left(A_{\text {eff }} / A\right)$ and the ratio $W_{y}$, eff $/ W_{y}$ are reported, as well as the ratio $y_{0} / d$, i.e. the distance between the shear center and the centroid $\left(\mathrm{y}_{0}\right)$ over the distance between the centroid and the web (d). The effective area and the effective section modulus of the upright section have been derived, 
Table 1

Key geometric parameters of the upright cross-section.

\begin{tabular}{lllll}
\hline & IPA1 & IPB1 & IPC1 & IPD1 \\
\hline Material & S420 MC & S355 & S350 GD & S355 MC \\
$\boldsymbol{\alpha}$ & 60 & 50 & 45 & 42,5 \\
$\boldsymbol{\beta}$ & 35,5 & 25,5 & 30,5 & 25,75 \\
$\boldsymbol{\gamma}$ & 30 & 41 & 37,5 & 32,5 \\
$\boldsymbol{\chi}$ & 60 & 30 & 28 & 23,5 \\
$\boldsymbol{\xi}$ & 25,95 & 25 & 25 & 25 \\
$\boldsymbol{\eta}$ & 26 & - & 25 & 25 \\
$\boldsymbol{\omega}$ & - & - & 25 & - \\
$\mathbf{A e f f} / \mathbf{A}$ & 0,81 & 0,98 & 0,85 & 0,84 \\
$\mathbf{W y}, \mathbf{e f f} / \mathbf{W y}$ & 0,84 & 0,93 & 0,92 & 0,84 \\
$\mathbf{I y / I z}$ & 5,15 & 1,86 & 1,88 & 2,06 \\
$\mathbf{\rho y} / \mathbf{\rho z}$ & 2,27 & 1,36 & 1,37 & 1,43 \\
$\mathbf{W y / W z}, \mathbf{l e f t}$ & 2,02 & 1,35 & 1,22 & 1,25 \\
$\mathbf{W y / W z}, \mathbf{r i g h t}$ & 3,13 & 1,69 & 1,91 & 1,90 \\
$\mathbf{y 0 / d}$ & 1,82 & 2,06 & 2,20 & 2,18 \\
\hline
\end{tabular}

Table 2

Key geometric parameters of the pallet beam cross-section.

\begin{tabular}{lllll}
\hline & IPA1 & IPB1 & IPC1 & IPD1 \\
\hline Material & S355 MC & S275 N/NL & S355 MC & S355 MC \\
$\mathbf{\Omega}$ & 30 & 33,33 & 26,67 & 33,33 \\
$\boldsymbol{\Delta}$ & 100 & 86,67 & 66,67 & 83,33 \\
$\mathbf{I y} / \mathbf{I z}$ & 8,97 & 12,5 & 5,73 & 4,36 \\
$\mathbf{\rho y} / \boldsymbol{\rho z}$ & 3,00 & 3,53 & 2,39 & 2,09 \\
$\mathbf{W y} / \mathbf{W z}$ & 2,69 & 5,51 & 2,27 & 1,72 \\
\hline
\end{tabular}

respectively, from stub column tests and bending tests, performed according to EN15512 [38]. This experimental evaluation accounts for cold manufacturing processes, perforations, local and distortional buckling phenomena and their natural interactions.

The uprights are perforated to facilitate the connections with the beams and the bracing members. The perforation system is regular along their whole length so that the structure is quickly assembled, and the height of the inter-storey can be easily adapted with changing pallet loads on the beams over time. Front side perforations have proprietary shapes depending on the hooking system of the beam end connectors. On the other hand, all the perforations on lateral side are circular, enabling easy bolted bracing connections with the upright frame. The presence of perforations complicates the analytical calculation, therefore the design of the uprights are based on experiments, which provided the effective cross section values (e.g. area, section modulus). The configuration of the perforations for all specimens is schematically shown in Fig. 5c, and summarized for each upright specimen in Table 1.

Uprights have been designed taking into account their perforated geometry. The performance of each specimen's upright section has been determined by means of tests in reference to EN 15512 [38]. To determine the influence of the distortional buckling mode on the axial load capacity of the upright section, reduction parameters have been obtained from the tests, which correct the theoretically determined axial loading capacity. In particular, $A_{\text {eff }}$ obtained from stub column tests is modified for distortional buckling according to the procedure defined in 9.7.2.c of EN 15512 [38], which requires a distortional buckling test on a column length equal to the length of the single bracing panel.

The geometrical characteristics of all four specimens have been defined considering the common rack configurations on the market, and meeting the dimensional limits of the testing facility. Therefore, all test specimens are composed of four loaded levels of $2 \mathrm{~m}$ height, one braced upright frame of $1.1 \mathrm{~m}$ width, and two bays
Table 3

Key geometric parameters of the base plate connections.

\begin{tabular}{lllll}
\hline & IPA1 & IPB1 & IPC1 & IPD1 \\
\hline $\boldsymbol{\zeta}$ & 22,5 & 18 & 13,33 & 36,2 \\
$\boldsymbol{\mu}$ & 25 & 40 & 27,5 & 30 \\
$\boldsymbol{\kappa}$ & - & 12 & 7,5 & 11,75 \\
$\boldsymbol{\varepsilon}$ & 18 & 32 & 20,83 & - \\
$\theta$ & 15,83 & 27,4 & 8,33 & 11 \\
\hline
\end{tabular}

Table 4

Geometrical characteristics of rack specimens.

\begin{tabular}{lllll}
\hline & IPA1 & IPB1 & IPC1 & IPD1 \\
\hline Cross-aisle configuration & X-bracing & D-bracing & D-bracing & D-bracing \\
Frame depth & $1100 \mathrm{~mm}$ & $1100 \mathrm{~mm}$ & $1100 \mathrm{~mm}$ & $1100 \mathrm{~mm}$ \\
Bay length (net span) & $2706 \mathrm{~mm}$ & $2700 \mathrm{~mm}$ & $2700 \mathrm{~mm}$ & $2700 \mathrm{~mm}$ \\
Rack height & $7970 \mathrm{~mm}$ & $8010 \mathrm{~mm}$ & $7990 \mathrm{~mm}$ & $8000 \mathrm{~mm}$ \\
First load level & $2042 \mathrm{~mm}$ & $2010 \mathrm{~mm}$ & $1992 \mathrm{~mm}$ & $2000 \mathrm{~mm}$ \\
Upper floor heights & $1976 \mathrm{~mm}$ & $2000 \mathrm{~mm}$ & $2000 \mathrm{~mm}$ & $2000 \mathrm{~mm}$
\end{tabular}

Table 5

Parameters used in the design of tests specimens.

\begin{tabular}{|c|c|c|c|c|}
\hline & IPA1 & IPB1 & IPC1 & IPD1 \\
\hline $\begin{array}{l}\text { Design Earthquake } \\
\text { Intensity }\end{array}$ & $\begin{array}{l}\text { Low } \\
\text { seismicity }\end{array}$ & $\begin{array}{l}\text { Moderate } \\
\text { seismicity }\end{array}$ & $\begin{array}{l}\text { Low } \\
\text { seismicity }\end{array}$ & $\begin{array}{l}\text { Low } \\
\text { seismicity }\end{array}$ \\
\hline $\mathbf{T}(\mathbf{s})$ & 2,29 & 3,36 & 2,94 & 3,22 \\
\hline $\begin{array}{l}\text { Mass participation } \\
\text { (\%) }\end{array}$ & 84 & 90 & 89 & 87 \\
\hline Pallet mass & \multicolumn{4}{|l|}{$800 \mathrm{~kg}$} \\
\hline Soil Type & \multicolumn{4}{|l|}{$\mathrm{C}$} \\
\hline Importance Class & \multicolumn{4}{|l|}{ II } \\
\hline Design Life & \multicolumn{4}{|c|}{30 years $\rightarrow \gamma_{1}=0,84$ (normal use of the racks) } \\
\hline $\mathbf{E D}_{3}$ & 0,67 & & & \\
\hline q-design & 2 & 2 & 1.5 & 2 \\
\hline
\end{tabular}

Table 6

Design concepts and upper limit reference values of the behavior factor [37].

\begin{tabular}{ll}
\hline Design Concept & $\begin{array}{l}\text { Range of reference values of the be- } \\
\text { havior factor } \mathbf{q}\end{array}$ \\
\hline $\begin{array}{l}\text { Concept A Low dissipative structural } \\
\text { behavior }\end{array}$ & $\mathrm{q} \leq 2$ \\
$\begin{array}{c}\text { Concept B Dissipative structural } \\
\text { behavior }\end{array}$ & $\mathrm{q}>2$ \\
\hline
\end{tabular}

of $2.7 \mathrm{~m}$ length. Slight differences in the precise frame dimensions shown in Table 4 are due to the proprietary component arrangements of each rack producer, which are small enough to be disregarded. Vertical bay loading of the specimens are provided by concrete blocks of $8 \mathrm{kN}$ loaded on wooden pallets, which is an average value for the merchandise used commonly in practice $[31,32]$. Three loaded pallets are placed on each bay of the rack specimens to simulate the fully-loaded service condition.

The specimens have been designed by the four industrial rack producers according to their daily practice, and using the design parameters recommended by European Federation of Materials Handling (FEM) standards [33-37], and EN 15512 [38], which are summarized in Table 5 . Specimen IPB1 has been designed for moderate seismicity, whereas IPA1, IPC1 and IPD1 for low seismicity. 
Since the case studies represent racks for common storage applications in standard warehouse conditions, a design life of 30 years is considered for all specimens. Importance factor is taken as $\gamma_{\mathrm{I}}=0.84$, which corresponds to the second importance class. In the analysis, a modified seismic response spectrum is used which takes into account the energy dissipation due to pallet-beam friction, damping due to the movement of stored products and pallet flexibility. These typical phenomena of racking structures that are not explicitly considered in the mathematical formulation of the spectrum is considered within a global reduction factor $\mathrm{ED}_{3}$. The value of $\mathrm{ED}_{3}$ has been used as recommended by the reference standard reference [37]. Besides this coefficient, a behavior factor is also taken into account in the design spectrum, the value of which depends on the type of design approach.

In general, rack specimens can be designed according to two different concepts. Either assuming low dissipative structural behavior; in this case the seismic action is calculated by means of elastic global analysis without taking into account relevant nonlinear material behavior, or, with dissipative structural behavior; in this case controlled plastic deformation is foreseen for the structure. The range of behavior factor values is defined in Table 6 . The design of test specimens have been made according to the low dissipative approach.

A minimum value 1.5 of q-factor is recommended for low dissipative concept, as used for IPC1. The behavior factor $\mathrm{q}=2$ has been adopted for IPA1, IPB1, IPD1 where the following conditions are met:

- at least one bolt is provided to secure the beam-end connector to the upright.

- the bolt is positioned above the center of gravity of the beam.

- washers are fitted under both the nut and bolt head and the nut is snug tight.

- the washer is such that the connector cannot disengage from the upright.

Proprietary semi-rigid beam-end and base plate joints have been used by each partner in the structural design, whose response properties were characterized by experimental assessment according to the EN15512 [38]. The main geometric properties of base joints and the implementation of the bolts, which connect the upright to the vertical gusset plate and the base plate to the floor, are shown in Fig. 6 and are reported in Table 3. The influence of loading on the behavior of the floor connections is investigated testing them under different axial loads, and reported elsewhere [28]. Specifically, the upright-base tests are performed on three

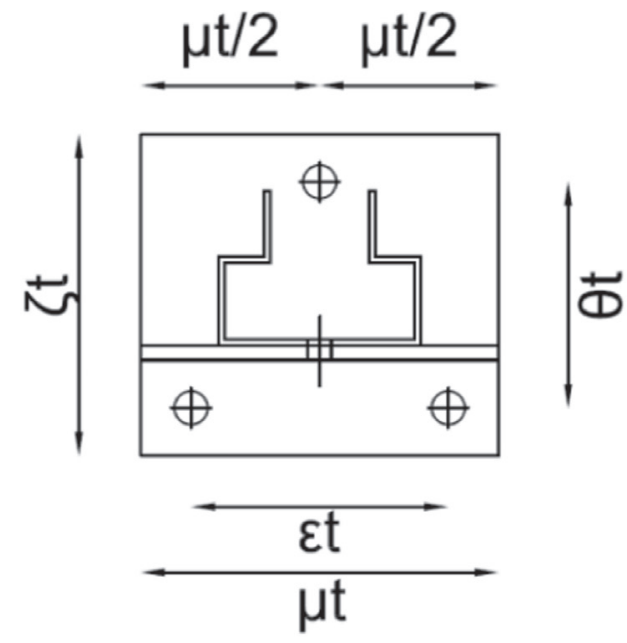

a. IPA1

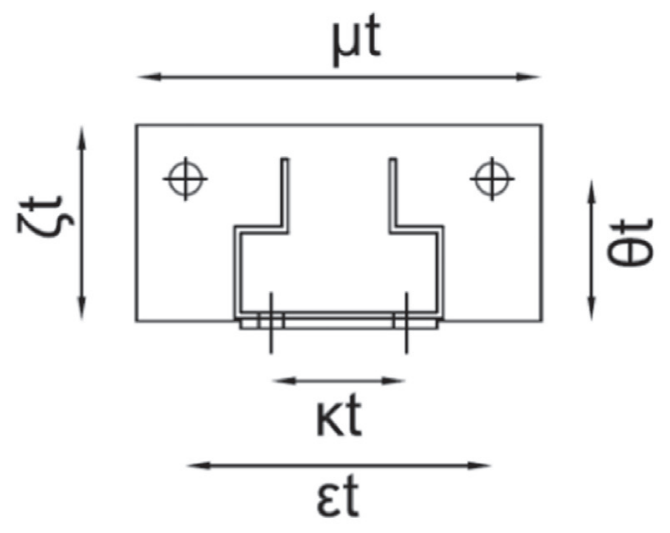

c. IPC1

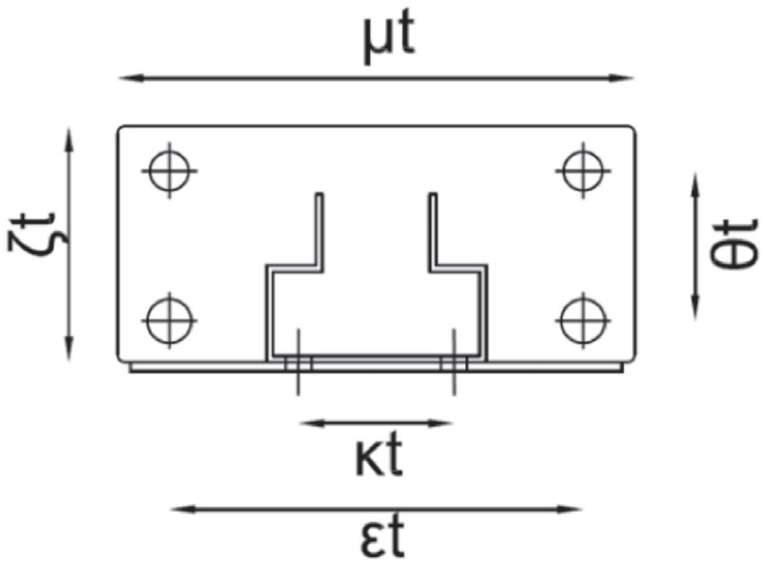

b. IPB1

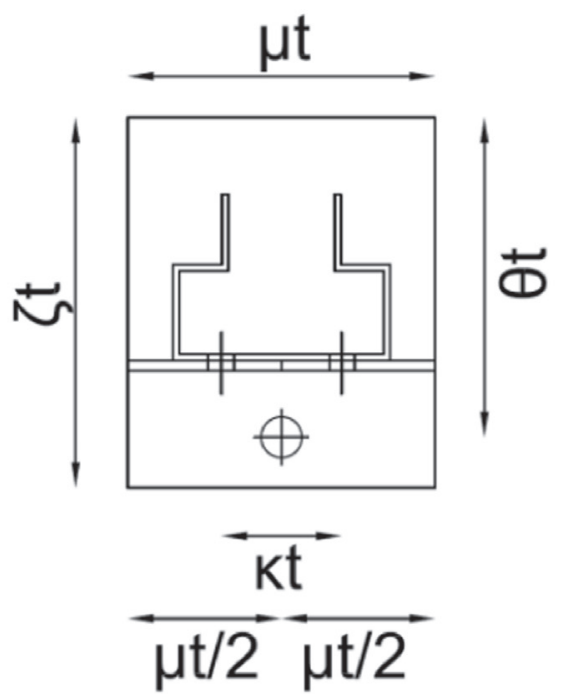

d. IPD1

Fig. 6. The base plate connection geometry (t: thickness of base plate). 


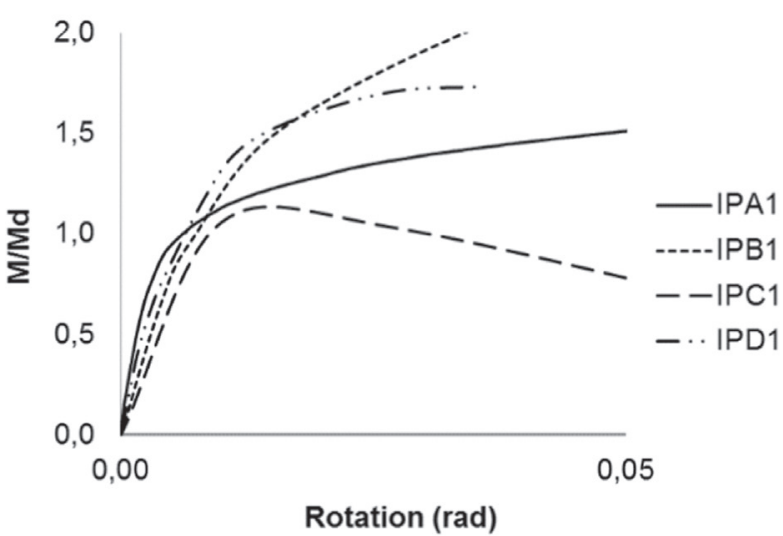

a. Floor connections

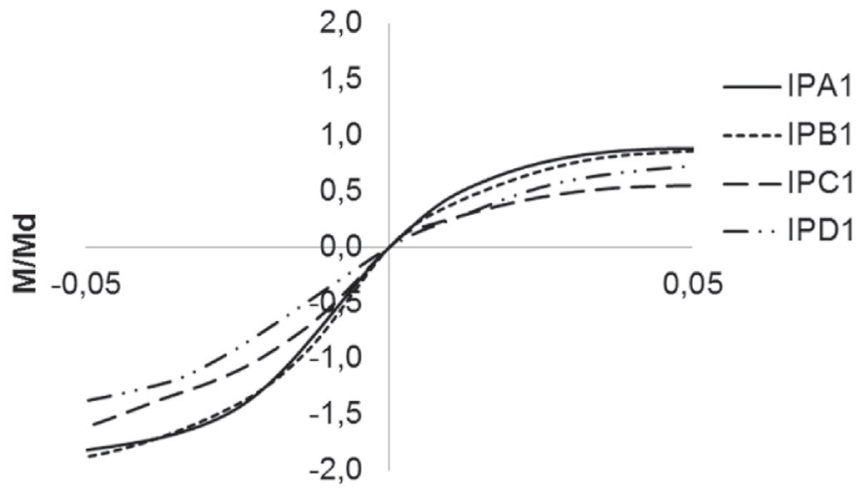

Rotation (rad)

b. Upright-beam end connections

Fig. 7. Flexural stiffness curves of floor and upright-beam end connections. a) Floor connections. b) Upright-beam end connections.

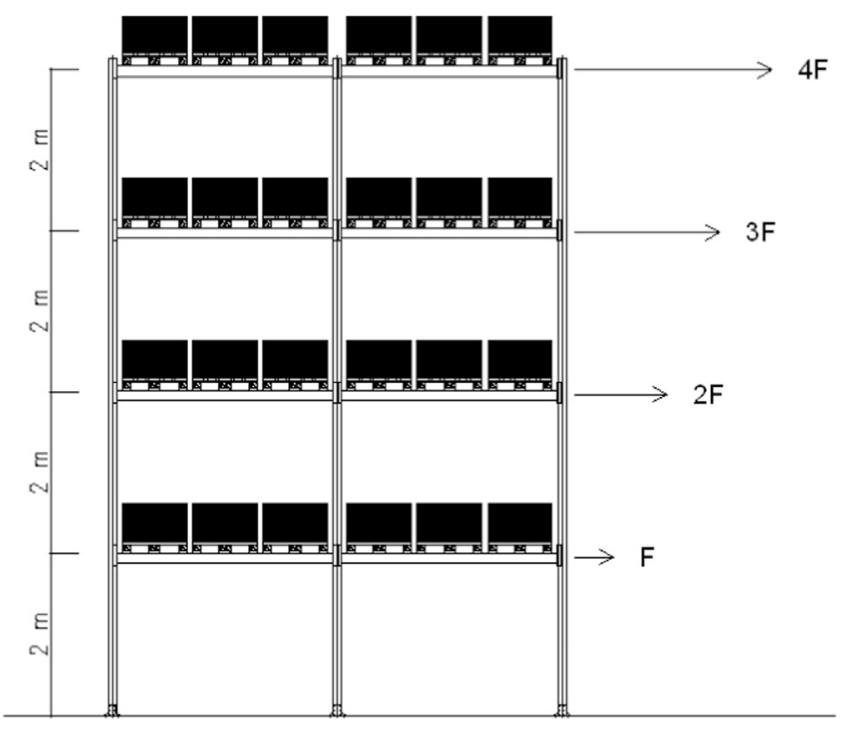

Fig. 8. Loading scheme. load levels associated to $0 \%, 50 \%$ and $100 \%$ payload conditions. Experimental stiffness curves of the floor and upright-beam connections are normalized by their design moment resistance $\left(\mathrm{M}_{\mathrm{d}}\right)$ and shown in Fig. 7. The floor connection stiffness curves shown in this figure are plotted for $100 \%$ payload $(48 \mathrm{kN})$, with reference to the fully loaded central uprights.

Horizontal push-over static loading has been applied with an inverted triangular pattern (Fig. 8), which is justified by the high modal mass participation of the first natural period of the test specimens in the longitudinal direction. The level loads are applied proportionally to the dynamic inertia of each level, which is a typical force-controlled loading condition [39,40].

The displacements of relevant nodes are monitored and recorded. For this purpose, twelve potentiometric displacement transducers were used. Eight transducers were placed, two for each level of the rack, in order to monitor the longitudinal backside and front side down-aisle direction displacements, while four transducers were placed backside at the second and fourth floor on the left and right side of the rack, to measure the displacements in the cross aisle direction. The general test layout is shown in the Fig. 9. During tests, photographic surveys were carried out with the dual purpose of obtaining

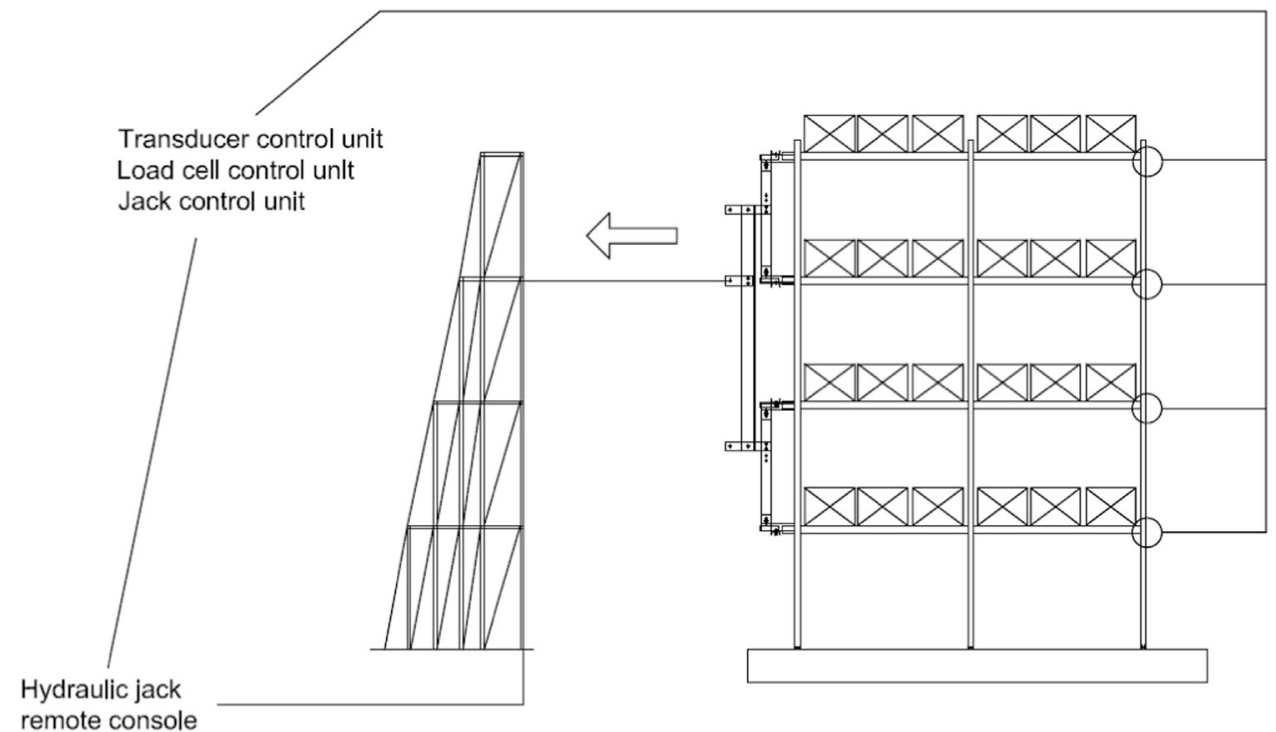

Fig. 9. General test layout. 
photographic documentation of the work and saving backup information of the deformed shapes of the structure [41] (Fig. 10).

\section{Test results}

The test results are presented as global capacity curves, plotted in terms of top displacement values versus total base shear

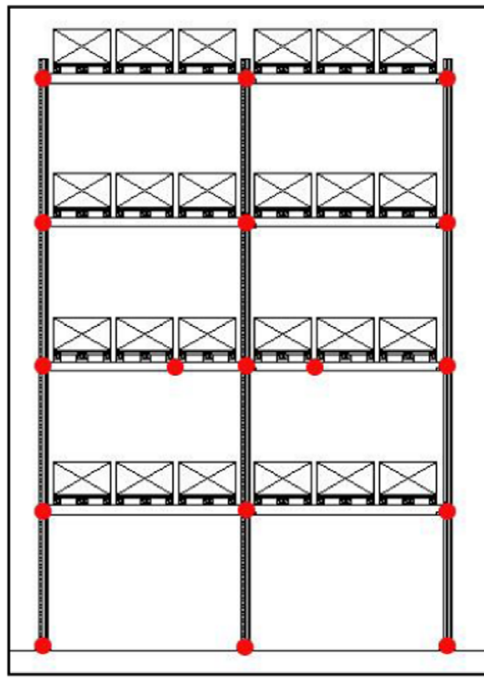

a) Targets disposition

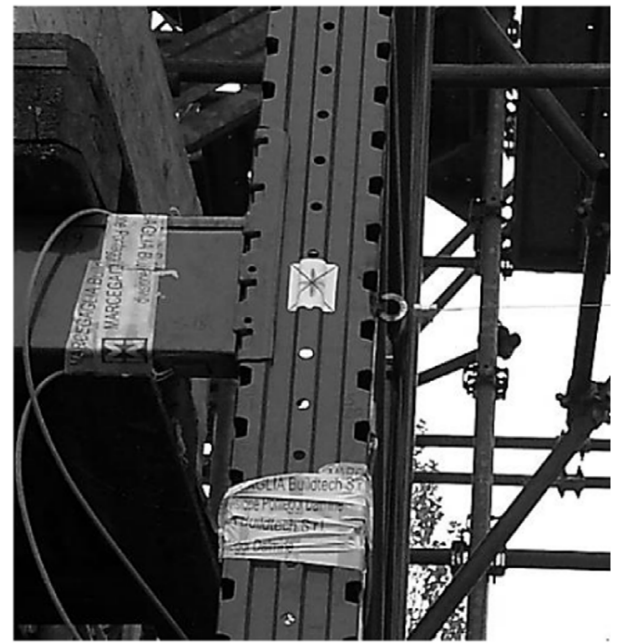

b) Target bonded to a joint

Fig. 10. Photogrammetric monitoring. a) Targets disposition. b) Target bonded to a joint.

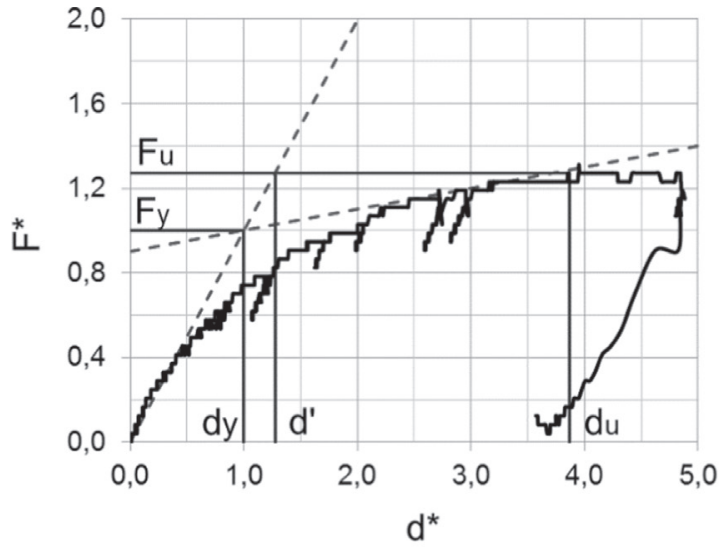

a. IPA1

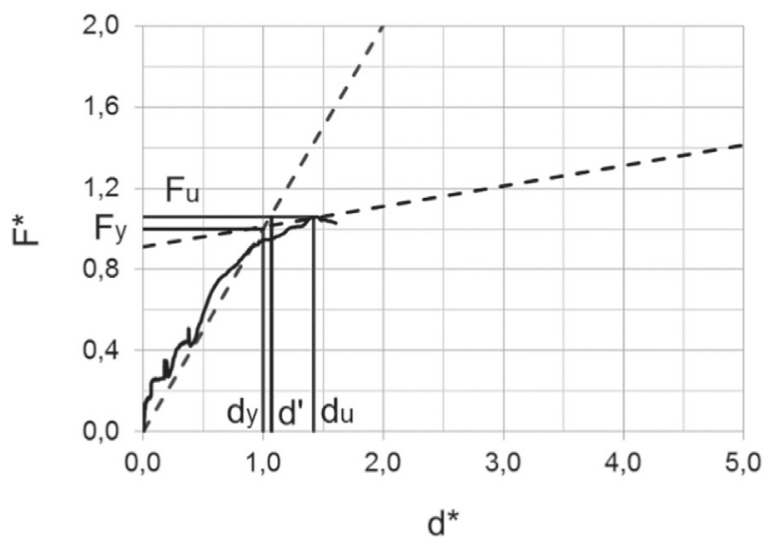

c. IPC1

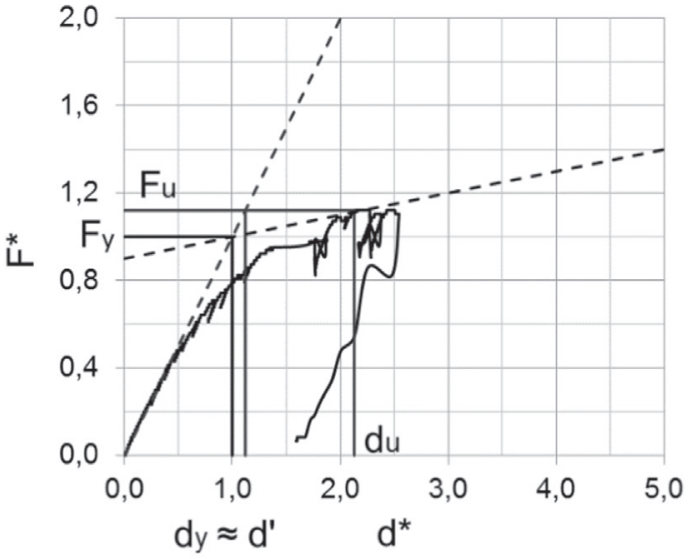

b. IPB1

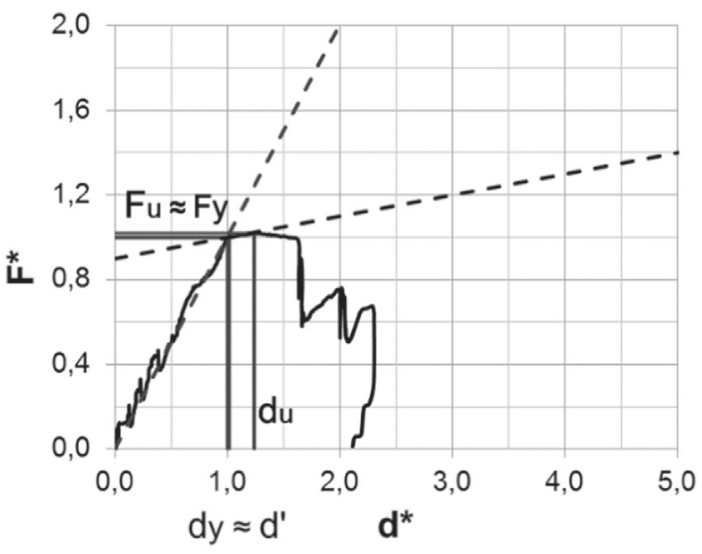

d. IPD1

Fig. 11. Global force-displacement diagrams of tests. 
(Fig. 11). After a careful analysis of the different approaches proposed in the literature [42-47] the authors proposed the following procedure, in order to evaluate the global yield base shear $\left(\mathrm{F}_{\mathrm{y}}\right)$, and corresponding global yield displacement $\left(\mathrm{d}_{\mathrm{y}}\right)$ values, making reference to ECCS45 [42]:

i. Initial stiffness of the curves are approximated by the tangent slope obtained at their origin (Fig. 12);

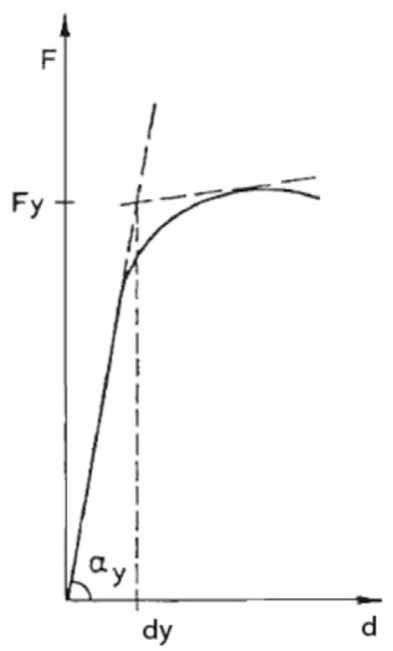

Fig. 12. Definition of yield force by ECCS45 [42].

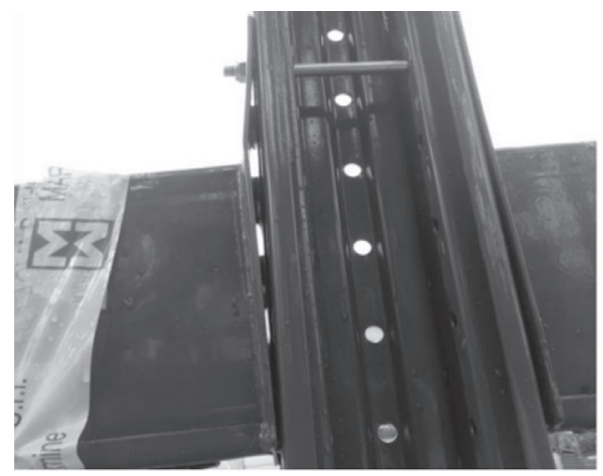

a. IPA1

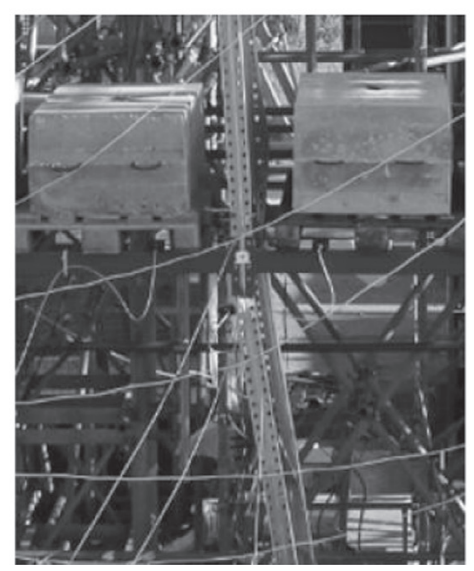

c. IPC1 ii. The global yield base shear $F_{y}$ and the corresponding yield displacement $\mathrm{d}_{\mathrm{y}}$ are deduced by locating the $1 / 10$ of the initial stiffness slope on the global force-deformation curves. The intersection of the two tangents defines the level of $F_{y}$, and the displacement corresponding to the intersection is defined as $\mathrm{d}_{\mathrm{y}}$;

iii. Base shear forces $\left(\mathrm{F}^{*}\right)$ have been normalized on the global yield shear force $\left(F_{y}\right)$ :

$\frac{\boldsymbol{F}}{\boldsymbol{F}_{\boldsymbol{y}}}=\boldsymbol{F}^{*}$

iv. Displacements $\left(d^{*}\right)$ have been normalized on the yield displacement of the frame $\left(\mathrm{d}_{\mathrm{y}}\right)$

$$
\frac{d}{d_{y}}=d^{*}
$$

As can be seen in Figs. 11a and b, specimens IPA1 and IPB1 sustained a large global deformation in the plastic range, between the onset of yield and ultimate collapse loads $\left(\mathrm{F}_{\mathrm{y}}, \mathrm{F}_{\mathrm{u}}\right)$. This significant deformation capacity was mainly provided by the inelastic deformations of beam-end connectors (Fig. 13.a.b.), diffused in the whole structure, the rest of the structural elements (uprights and pallet beams) remaining undamaged. When these two specimens were unloaded, a partial recovery of elastic deformation can be observed from their capacity curves, confirming a ductile global behavior as described in Fig. 14a.

On the other hand, global deformation sustained by specimens IPC1 and IPD1 in the plastic range was very limited (Figs. 11c and d). Both specimens had a quite sudden collapse soon after

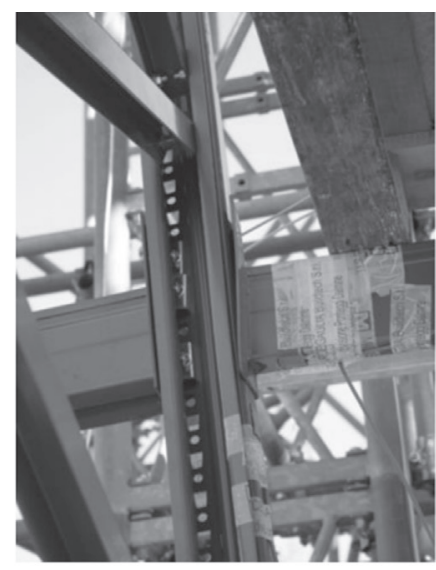

b. IPB1

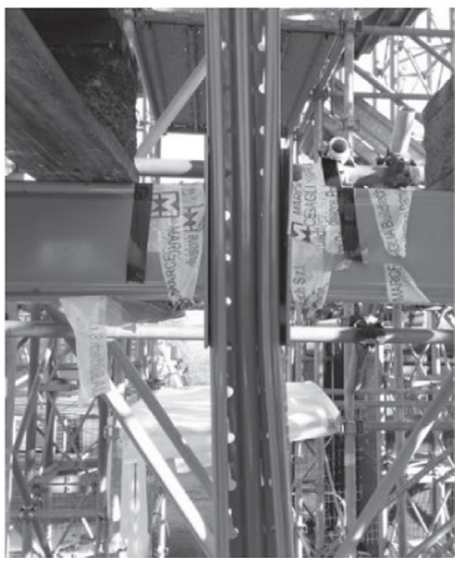

d. IPC1

Fig. 13. Examples of ductile (a, b) and brittle (c,d) upright-beam connection details. 


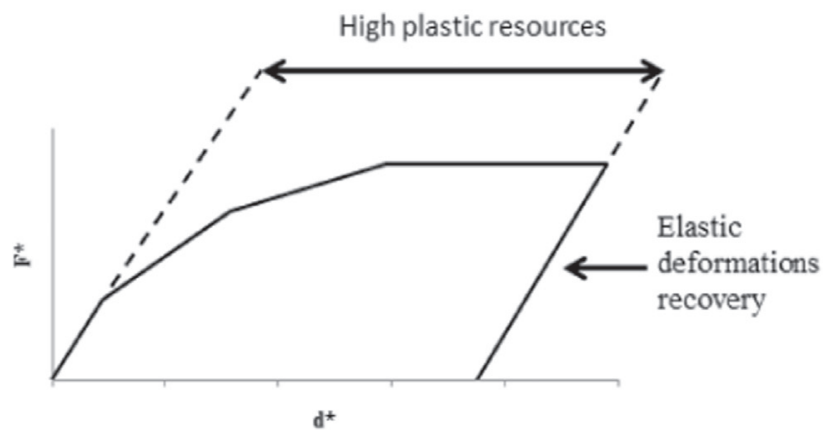

a. Ductile situation

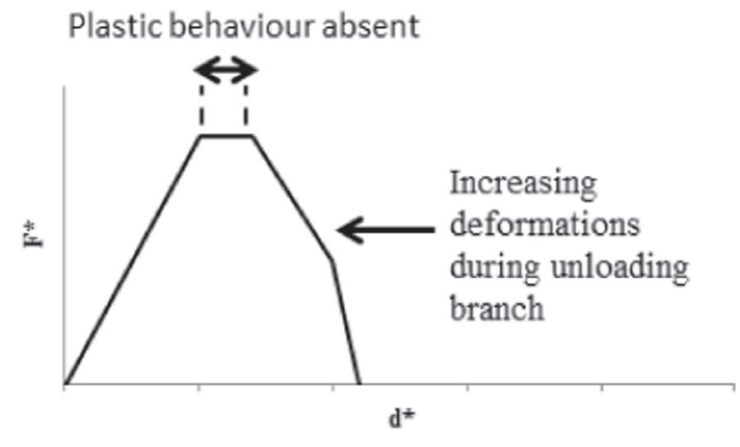

b. Brittle Situation

Fig. 14. Schematic capacity curves. a) Ductile situation. b) Brittle Situation.

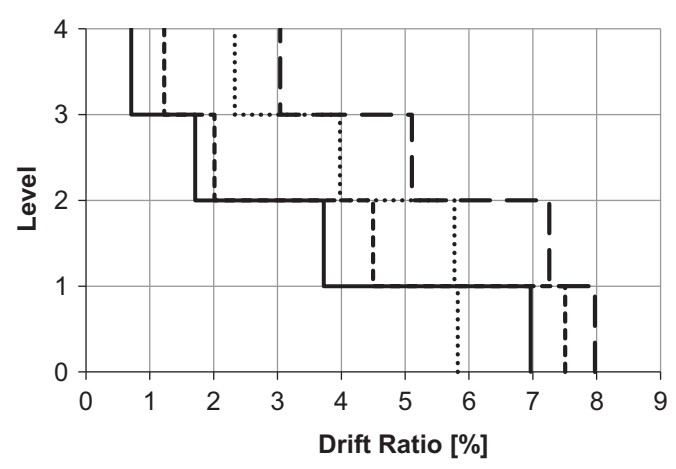

a. Drift ratio

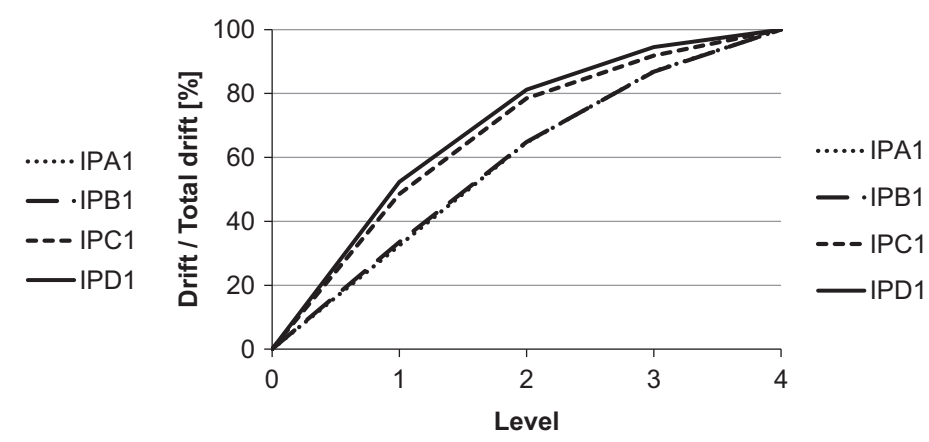

b. Cumulative drifts at each level

Fig. 15. Inter-storey drift ratio and floor displacements. a) Drift ratio. b) Cumulative drifts at each level.

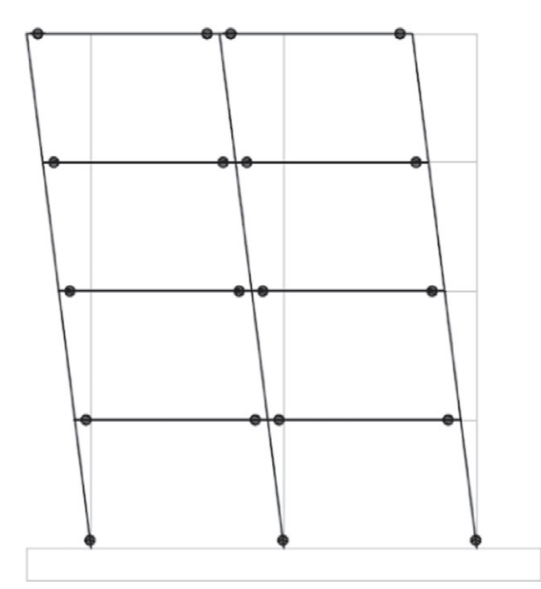

a) Global failure mechanism

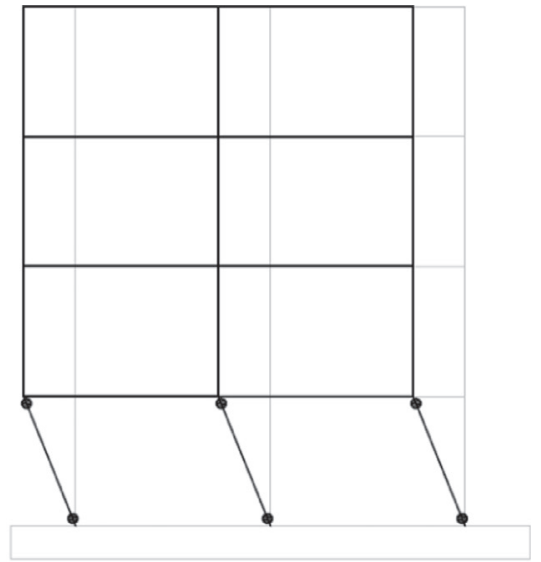

b) Soft story failure mechanism

Fig. 16. Different types of collapse mechanism.

reaching their global yield limits. In specimen IPC1, all the inelastic deformation was concentrated at the uprights just below the upright-beam connections (Fig. 13c), while in specimen IPD1, the first-level upright profiles were damaged in correspondence to the upright-beam connections (Fig. 13d). In these latter two cases, the absence of the elastic recovery after the tests indicate a global brittle behavior as described in Fig. 14b.

In Fig. 15, inter-storey drifts obtained at the last horizontal loading step just before collapse have been presented. It can be observed that while in specimens IPA1 and IPB1 the story drifts are essentially linearly distributed along the height of the structure, in case of IPC1 and IPD1, more than 50\% of the drifts were concentrated at the first level (Fig. 15b). This comparison also highlights that the collapse of the latter two specimens is characterized by the onset of a soft storey mechanism with a formation of plastic hinges in the base connections, and in the uprights at the 
first inter-storey level, as described schematically in Fig. 16b. Global ductility of the specimens can also be derived from Fig. 17, which compares the deformation capacities of each tested specimen with respect to the ultimate horizontal load they resisted before collapse.

The main cause of the soft storey behavior occurring in specimens IPC1 and IPD1 was due to the low stiffness values of their upright base plates, which lost their initial stiffness and behaved like hinges after reaching a certain level of horizontal load. This loss of stiffness caused the formation of plastic hinges on the uprights and beam end connectors just below the first level, and after this point, the specimens could not sustain any more horizontal load. Moreover, in case of IPD1, strong localized pressures led to a distortion of upright sections at the beam-upright joints of the first two levels, and this caused distortional buckling deformations to develop at the first two inter-stories of the structures inducing the soft storey mechanism (Fig. 13.c.d). Distortional buckling, also known as "stiffener buckling" or "local-torsional buckling", is caused by the rotation of the flange at the flange/web junction, and occurs frequently in members with edge stiffened elements. At the end of the test, distortional buckling was visible

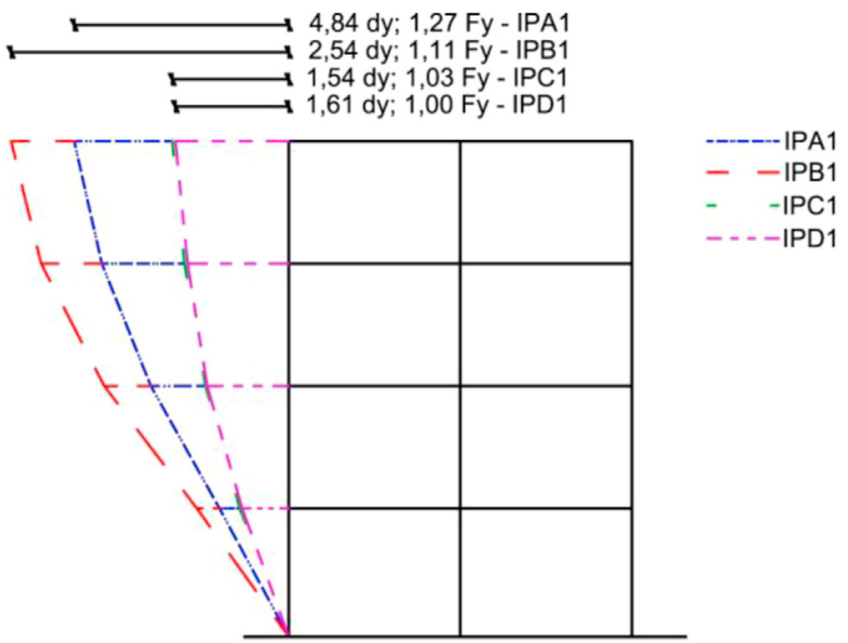

Fig. 17. Deformed shape and ultimate load before collapse plotted for each specimen. in the uprights along the first and second level; in fact the distortion in the uprights was favoured by the absence of rigid constraints that could have been given by the bracing system joints in cross aisle direction. The two cases with and without a rigid constraint in the beam-upright connection are shown in Fig. 18, which refer to the first level of the IPD1 specimen.

From the measurements obtained by the transducers placed on both uprights of the upright frames, it could be concluded that none of the specimens exhibited global torsional behavior, thanks to the symmetry of their structural configuration.

\section{Assessment of behavior factor (Q)}

The resistance and energy-dissipation capacity of a structure are related to the extent to which its nonlinear response is exploited. In operational terms, such balance between resistance and energy-dissipation capacity is characterized by the values of the behavior factor q. The q-factor is defined as the product of the overstrength $\Omega$, and the ductility ratio $\mu=\mathrm{q}_{0}$.

$\boldsymbol{\Omega}=\frac{\boldsymbol{F}_{\boldsymbol{u}}}{\boldsymbol{F}_{\boldsymbol{y}}} ; \boldsymbol{q}_{0}=\frac{\boldsymbol{d}_{\boldsymbol{u}}}{\boldsymbol{d}^{\prime}} ; \boldsymbol{q}=\mathbf{\Omega} \cdot \mathbf{q}_{0}$

where:

- $F_{y}$ is the global yield base shear

- $F_{u}$ is the ultimate load before collapse

- $\mathrm{d}_{\mathrm{u}}$ is the displacement associated to $\mathrm{F}_{\mathrm{u}}$

- $d$ ' is the displacement associated to the intersection between the tangent slope and $\mathrm{F}_{\mathrm{u}}$

These values are shown for each specimen in Fig. 11.

Table 7

q-factor values of unbraced racks.

\begin{tabular}{lllll}
\hline & IPA1 & IPB1 & IPC1 & IPD1 \\
\hline$\Omega$ & 1,27 & 1,12 & 1,06 & 1,02 \\
qo & 3,03 & 1,90 & 1,33 & 1,22 \\
$\mathbf{q}$ & $\mathbf{3 , 8 5}$ & $\mathbf{2 , 1 3}$ & $\mathbf{1 , 4 1}$ & $\mathbf{1 , 2 4}$ \\
q DESIGN & $\mathbf{2 , 0 0}$ & $\mathbf{2 , 0 0}$ & $\mathbf{1 , 5 0}$ & $\mathbf{2 , 0 0}$ \\
q/q $q_{\text {DESIGN }}$ & 1,93 & 1,07 & 0,94 & 0,62 \\
\hline
\end{tabular}

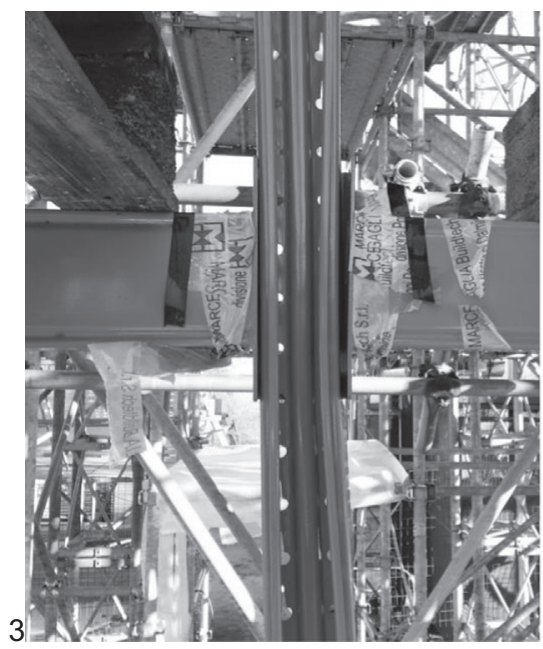

a. First level beam-upright connection with upright damage

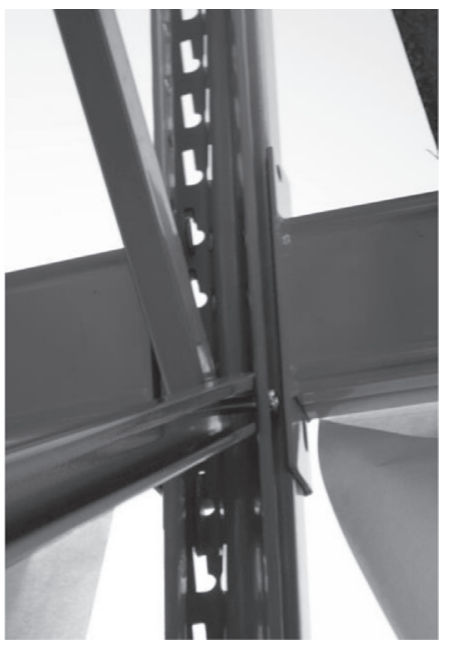

b. First level beam-upright connection where the upright bracing node provides stiffness and avoid local upright damage

Fig. 18. Difference between two types of beam-upright joints. 
Table 7 presents the q values estimated for each test specimen. Global ductility of specimens IPA1 and IPB1 resulted in moderate $\mathrm{q}$ values, showing an appropriate capacity of these racks to dissipate earthquake forces. On the contrary, IPC1 and IPD1 had lower q values as a result of their global brittle behavior. It should be also noted that the q values obtained by the experimental tests of the latter specimens are lower than the ones assumed in design phase (Table 7). This means that the design q-values can be acceptable only when the inelastic behavior is distributed homogenously over the full height of the structure, and this should be carefully investigated during the design phase.

\section{Conclusions}

This study presents the results of real scale push-over tests performed on fully-loaded steel storage rack specimens. From the capacity curves, global ductility of four commonly adopted storage rack typologies is quantified in terms of behavior factor $(q)$ values. The q values of the racks that showed a globally ductile behavior range from 2.13 to 3.85 , thanks to the diffuse exploitation of plastic deformation capacity in the beam-end connectors, robust base plate connections, and the rest of the structural elements (uprights, pallet beams) remaining undamaged. On the other hand, the $\mathrm{q}$ values of the racks that had a globally brittle collapse range from 1.24 to 1.41 . In the latter case, it was also seen that experimental values of q were lower than their design values. The global brittle collapse was caused by plastic hinges forming in the uprights at the first loading level, leading to a soft storey mechanism (Fig. 19).

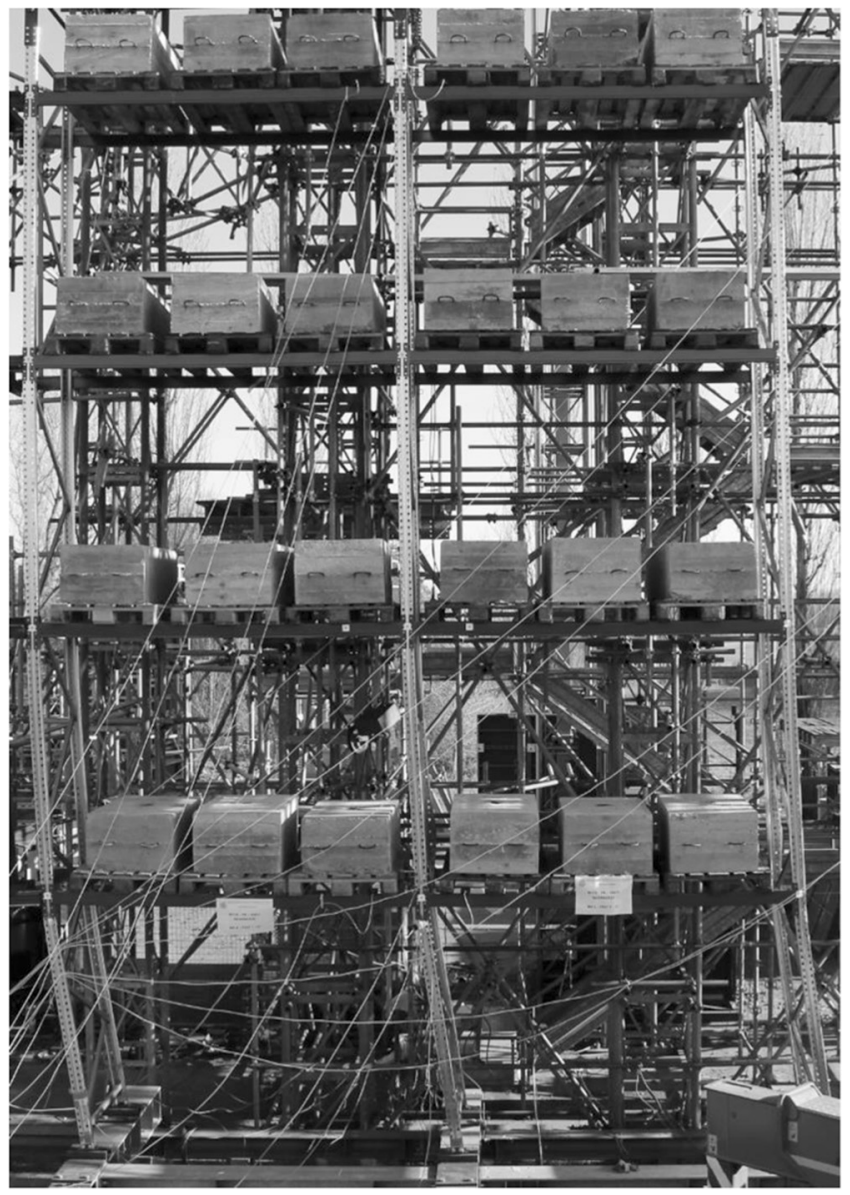

Fig. 19. Soft-storey mechanism formed at the first level.
Soft storey mechanism was caused when the base plate connections did not provide sufficient stiffness, which concentrated the rotation demands at the "more rigid" first floor beam-to-upright joints. This concentrated inelastic behavior was amplified by the distortion of the upright section due to the contact forces between upright and the beam-end connectors. Designers should pay attention to reduce this distortion by applying a stiffener in the upright-beam connections, or configuring the beam levels to match the level of the upright frame bracing connections.

The behavior factors commonly used in the design of unbraced racks (such as $\mathrm{q}=1.5$ or $\mathrm{q}=2.0$ ) can be reliable provided that the soft storey collapse mechanism is prevented, and the inelastic behavior is distributed homogenously over the full height of the structure. This should be carefully investigated and guaranteed in the design phase, improving the bending strength and the rotation capacity at the base, either by installing floor beams or designing the base-plates to have sufficient over-strength and stiffness, not to fail.

\section{Acknowledgments}

This paper presents the results of full scale tests performed within SEISRACKS2 project, which is carried out with the financial grant of the Research Program of the Research Fund for Coal and Steel of the European Commission (RFSR-CT-2011-00031). Precious comments of Prof. Claudio Bernuzzi, and the efforts of the Industrial Partners of the SEISRACKS2 project, who helped us improving the quality of the article, are deeply appreciated.

\section{References}

[1] C. Bernuzzi, European and United States approaches for steel storage pallet rack design: Part 1: Discussions and general comparisons, Thin-Walled Struct. 97 (2015) 308-320.

[2] T. Pekoz, G. Winter, Cold-formed steel rack structures In: W.W. Yu, (Ed.), in: Proc., 2nd Speciality Conference on Cold-Formed Steel Structures, Univ. Of Missiori Rolla, MO, 1973, pp. 603-615

[3] P. Carydis, C. Castiglioni, E. Lekkas, I. Kostaki, N. Lebesis, A. Drei, The Emilia Romagna, May 2012 earthquake sequence. The influence of the vertical earthquake component and related geoscientific and engineering aspects (Pavia, April-Sept)Ing. Sismica, XXIX, N. 2-3, 2012, pp. 31-58.

[4] EPICentre Field Observation Report No. EPI-FO-290512, The 29th May 2012 Emilia Romagna Earthquake, UCL Department of Civil, Environmental and Geomatic Engineering, 21/06/2012.

[5] EN1998-1-1, Design of structures for earthquake resistance, 2005.

[6] C. Bernuzzi, C.A. Castiglioni, Experimental analysis on the cyclic behaviour of beam-to-column joints in steel storage pallet racks, Thin-Walled Struct. 39 (2001) 841-859.

[7] N. Baldassino, C. Bernuzzi, Analysis and behaviour of steel storage pallet racks Thin-Walled Struct. 37 (4) (2000) 277-304

[8] N. Baldassino, R. Zandonini, Numerical and Experimental Analysis of BasePlate Connections of Steel Storage Pallet Racks, Proc. of XVIII Conference C.T.A., Venezia, 2001 pp. 127-136.

[9] N.W. Murray, Stability analysis of drive-in racking storage systems, Proc. Int Conf. on Structural Stability and Design, Balkema Netherlands, 1995, pp. 189195.

[10] B.P. Gilbert, K.J.R. Rasmussen, Determination of the base plate stiffness and strength of steel storage racking system, J. Constr. Steel Res. 67 (6) (2011) 1031-1041 (2011).

[11] B.P. Gilbert, K.J.R. Rasmussen, Bolted moment connections in drive-in and drive-through steel storage racks, J. Constr. Steel Res. 66 (6) (2010) 755-766.

[12] A. John, Blume \& Associates, Seismic Design Examples of Industrial Storage Racks", Report prepared for the Rack Manufacturer's Institute, San Francisco, CA, 1973.

[13] H. Krawinkler, N.G. Cofie, M.A. Astiz, C.A. Kircher, Experimental Study on the Seismic Behaviour of Industrial Storage Racks, Report No. 41 the John A. Blume Earthquake Engineering Center, Department of Civil Engineering, Stanford University Stanford, CA, 1979.

[14] C.K. Chen, R.E. Scholl and J.A. Blume, Seismic Study of Industrial Storage Racks, Report prepared for the National Science Foundation and for the Rack Manufacturers Institute and Automated Storage and Retrieval Systems (Sections of the Material Handling Institute), A. John, Blume \& Associates, San Francisco, 
CA, 1980.

[15] A. Filiatrault, Shake-Table Tests of Storage Racks and Contents. Presentation material at the April 12, 2001 Seismic Safety Commission Hearing on Industrial Storage Racks, San Francisco, CA, 2001.

[16] A. Filiatrault A. Wanitkorkul. Shake-Table Testing of Frazier Industrial Storage Racks, Report No. CSEE-SEESL-2005-02, Structural Engineering and Earth-quake Simulation Laboratory Departmental of Civil, Structural and Environ-mental Engineering, University at Buffalo 2004 State University of New York.

[17] B. Gilbert, K. Rasmussen, Drive-In Steel Storage Racks I: Stiffness Tests and 3D Load-Transfer Mechanisms, J. Struct. Eng. 138 (2) (2012) 135-147.

[18] C.A. Castiglioni, Dynamic Tests on Steel Pallet Racks, Costr. Met. 55 (3) (2003) 35-44.

[19] SEISRACKS RFSR-CT-2004-00045, Final Report, Research Program of the Research Fund for Coal and Steel RTD, May 2007.

[20] C.A. Castiglioni, A. Drei, P. Carydis, H. Mouzakis, Experimental assessment of static friction between pallet and beams in racking systems, J. Build. Eng., 6, Elsevier 2016, pp. 203-214.

[21] C.A. Castiglioni, Seismic Behavior Of Steel Storage Pallet Racking Systems ISSN 2198-7300, First edition, Springer International Publishing, 2016.

[22] C.A. Castiglioni, A. Kanyilmaz, H. Degee, C. Braham, B. Hoffmeister, C. Heinemeyer, I. Vayas, A. Adamakos, S. Sesana, B. Orsatti, J. Hermanek, J. Frederiks, T. Cudini, L. Rovere, D. Jehin, O. Kraus, D. Bakalbasis, SEISRACKS2 RFSRCT-2011-00031, Mid-term Report, Research Program of the Research Fund for Coal and Steel RTD, 2012.

[23] A. Castiglioni A. Kanyilmaz A. Drei B. Hoffmeister C. Heinemeyer H. Degee C. Braham I. Vayas K. Adamakos S. Sesana B. Orsatti, The "SEISRACKS2" EU-RFCS Research Project "Seismic Behaviour of Steel Storage Pallet Racking Systems" Part 1: Project Overview, XXIV Giornate Italiane della Costruzione in Acciaio, Torino, Italia, 2013.

[24] A. Castiglioni A. Kanyilmaz A. Drei B. Hoffmeister C. Heinemeyer H. Degee C Braham I. Vayas K. Adamakos N. Papadopoulos, The "SEISRACKS2" EU-RFCS Research Project "Seismic Behaviour of Steel Storage Pallet Racking Systems" Part 2: Experimental Activities, XXIV Giornate Italiane della Costruzione in Acciaio, Torino, Italia, 2013

[25] A. Castiglioni, A. Kanyilmaz, A. Drei, B. Hoffmeister, C. Heinemeyer, H. Degee, C. Braham, I. Vayas, K. Adamakos, N. Papadopoulos, The "SEISRACKS2" EU-RFCS Research Project "Seismic Behaviour of Steel Storage Pallet Racking Systems" Part 3: Numerical Activities, XXIV Giornate Italiane della Costruzione in Acciaio, Torino, Italia, 2013.

[26] A. Castiglioni, A. Kanyilmaz, Seismic Behaviour of Steel Storage Pallet Racking Systems, 5. Celik yapilar sempozyumu, Istanbul, Turkey, 2013.

[27] A. Castiglioni A. Kanyilmaz A. Drei B. Hoffmeister C. Heinemeyer H. Degee C. Braham I. Vayas K. Adamakos S. Sesana B. Orsatti. The "SEISRACKS2 EU-RFCS Research Project, Seismic Behavior of Steel Storage Pallet Racking Systems, Costruzioni metalliche, January 2015.

[28] A. Castiglioni, A. Kanyilmaz, A. Drei, B. Hoffmeister, C. Heinemeyer, H. Degee, C. Braham, I. Vayas, K. Adamakos, S. Sesana, B. Orsatti, SEISRACKS2, RFSRCT-2011-00031, Final Report, ISBN: 978-92-79-53897-1, Seismic Behaviou of Steel Storage Pallet Racking Systems, Research Program of the Research Fund for Coal and Steel RTD, 2014.
[29] A. Castiglioni, A. Kanyilmaz, M. Angeretti, G. Brambilla, G. Chiarelli, C. Bernuzzi, Experimental Results of Full Scale Push over Tests of Project SEISRACKS2 (Seismic Behaviour of Steel Storage Pallet Racking Systems), Second European Conference on Earthquake Engineering and Seismology, Istanbul, August 2014, pp. 25-29.

[30] EN 16681, Steel static storage systems - Adjustable pallet racking systems Principles for seismic design, 2014.

[31] DIN-EN 13698-1, PalLET productionS SPECIFICATION, Part 1: Construction specification for $800 \mathrm{mmX} 1200 \mathrm{~mm}$ flat wooden, 2004.

[32] Seismic Considerations for Steel Storage Racks Located in Areas Accessible to the Public FEMA 460 - September 2005, National Institute of Building Sciences Washington, D.C., 2005.

[33] FEM 10.2.04, Users Code, Federation Europeenne de la Manutention Section X Equipment et Proceedes de Stockage, 2001.

[34] FEM 10.2.03, Specifiers Guidelines, Federation Europeenne DE LA Manutention Section X Equipment ET Proceedes DE Stockage, 2000.

[35] FEM 10.2.05, Guidelines for working safely with lift trucks in pallet racking installations, Federation Europeenne DE LA Manutention Section X Equipment ET Proceedes DE Stockage, 2001.

[36] FEM 10.2.06, Design of Static Steel Shelving, Federation Europeenne DE LA Manutention Section X Equipment ET Proceedes DE Stockage, 2001.

[37] FEM 10.2.08, Recommendations for the Design of Static Steel Pallet Racking in Seismic Condition, Federation Europeen DE LA Manutention, December 2005.

[38]

EN 15512, Steel static storage systems - Adjustable pallet racking systems Principles for structural design, 2009.

[39] Chopra A.K. and Goel R.K. "A Modal Pushover Analysis Procedure to Estimate Seismic Demands for Buildings: Theory and Preliminary Evaluation", Report No. PEER 2001/03, Pacific Earthquake Engineering Research Center, University of California, Berkeley, 2001.

[40] FEMA-440, Improvement of Nonlinear Static Seismic Procedures, Applied Technology Council (ATC-55 Project), June 2005.

[41] G. D'Annibale, "Fotogram: restituzione di modelli 2D e 3D da sorgenti fotografiche", ISBN 8877584963 D. Flaccovio, Palermo IT, 2003

[42] N. ECCS 45 Recommended Testing Procedure For Assessing the Behaviour of Structural Steel Elements under Cyclic Loads, Technical Committee 1 Structural Safety and Loadings Technical Working Group 1.3 - Seismic Design, 1986.

[43] N.M., Newmark, W.J., Hall, Earthquake Spectra and design, EERI Monograph Series, Oakland, EERI, 1982

[44] ATC-34, A Critical Review of Current Approaches to Earthquake-resistant Design, Applied Technology Council, Redwood City, CA, 1995.

[45] ATC-63, Quantification of Building Seismic Performance Factors, Applied Technology Council, Redwood City, CA 2008, pp. 6-31.

[46] G. Ballio, C.A. Castiglioni, An approach to the seismic design of steel structures based on cumulative damage criteria, Earthq. Eng. Struct. Dyn. 23 (1994) 969-986.

[47] H. Krawinkler, A.A. Nassar, Seismic design based on ductility and cumulative damage demands and capacities. Nonlinear seismic analysis of RC buildings. P. Fajfar, H. Krawinkler, eds. Elsevier Science, New York, 1992, pp. 23-40. 